\title{
The Cytoskeletal Elements MAP2 and NF-L Show Substantial Alterations in Different Stroke Models While Elevated Serum Levels Highlight Especially MAP2 as a Sensitive Biomarker in Stroke Patients
}

\author{
Bianca Mages ${ }^{1}$ (1) $\cdot$ Thomas Fuhs $^{2}$. Susanne Aleithe ${ }^{3} \cdot$ Alexandra Blietz $^{3}$. Constance Hobusch ${ }^{1} \cdot$ Wolfgang Härtig $^{4}$. \\ Stefan Schob ${ }^{5}$ - Martin Krueger ${ }^{1}$. Dominik Michalski ${ }^{3}$
}

Received: 5 January 2021 / Accepted: 22 March 2021 / Published online: 1 May 2021

(C) The Author(s) 2021

\begin{abstract}
In the setting of ischemic stroke, the neurofilament subunit NF-L and the microtubule-associated protein MAP2 have proven to be exceptionally ischemia-sensitive elements of the neuronal cytoskeleton. Since alterations of the cytoskeleton have been linked to the transition from reversible to irreversible tissue damage, the present study investigates underlying time- and region-specific alterations of NF-L and MAP2 in different animal models of focal cerebral ischemia. Although NF-L is increasingly established as a clinical stroke biomarker, MAP2 serum measurements after stroke are still lacking. Therefore, the present study further compares serum levels of MAP2 with NF-L in stroke patients. In the applied animal models, MAP2-related immunofluorescence intensities were decreased in ischemic areas, whereas the abundance of NF-L degradation products accounted for an increase of NF-L-related immunofluorescence intensity. Accordingly, Western blot analyses of ischemic areas revealed decreased protein levels of both MAP2 and NF-L. The cytoskeletal alterations are further reflected at an ultrastructural level as indicated by a significant reduction of detectable neurofilaments in cortical axons of ischemia-affected areas. Moreover, atomic force microscopy measurements confirmed altered mechanical properties as indicated by a decreased elastic strength in ischemia-affected tissue. In addition to the results from the animal models, stroke patients exhibited significantly elevated serum levels of MAP2, which increased with infarct size, whereas serum levels of NF-L did not differ significantly. Thus, MAP2 appears to be a more sensitive stroke biomarker than NF-L, especially for early neuronal damage. This perspective is strengthened by the results from the animal models, showing MAP2-related alterations at earlier time points compared to NF-L. The profound ischemia-induced alterations further qualify both cytoskeletal elements as promising targets for neuroprotective therapies.
\end{abstract}

Keywords Cerebral ischemia $\cdot$ Stroke $\cdot$ NF-L $\cdot$ MAP2 $\cdot$ Biomarker $\cdot$ Atomic force microscopy

Martin Krueger and Dominik Michalski contributed equally

Bianca Mages

bianca.mages@medizin.uni-leipzig.de

Dominik Michalski

dominik.michalski@medizin.uni-leipzig.de

Institute of Anatomy, Leipzig University, Leipzig, Germany

2 Section of Soft Matter Physics, Faculty of Physics and Geosciences, Leipzig University, Leipzig, Germany

3 Department of Neurology, Leipzig University, Leipzig, Germany

4 Paul Flechsig Institute of Brain Research, Leipzig University, Leipzig, Germany

5 Department of Neuroradiology, Leipzig University, Leipzig, Germany

\section{Introduction}

As part of the neuronal cytoskeleton, neurofilaments, microtubules, and associated proteins not only maintain cellular stability but also impact on critical neuronal functions, such as the regulation of axonal caliber [1-3], conduction velocity [4], axonal transport [5-7], and synaptic function [8]. Therefore, it is not surprising that these elements play crucial roles in the pathogenesis of a variety of central nervous system disorders [9-11].

In the setting of stroke, an affection of the neuronal cytoskeleton is discussed to represent a key mechanism during the evolution of the ischemic lesion and hence the transition from reversible to irreversible tissue damage [12, 13]. Although 
ischemic stroke represents one of the leading causes of death worldwide $[14,15]$ and despite tremendous efforts in preclinical and clinical stroke research, acute therapies are still restricted to recanalizing approaches with intravenous thrombolysis and mechanical thrombectomy $[16,17]$. Therefore, the need for single or adjuvant neuroprotective treatments is still evident. However, even though cytoskeletal derangements were described in the context of ischemic stroke [18-23], neurofilaments and microtubule-associated proteins have so far been largely neglected as targets for neuroprotective approaches.

As one of the four neurofilament proteins of the central nervous system, the neurofilament-light chain (NF-L) is predominantly abundant in axons, whereas smaller amounts of NF-L can also be found in dendrites and neuronal somata [23-25]. Of note, NF-L has turned into focus of stroke research, as recent clinical studies demonstrated a correlation between peripheral serum NF-L levels and the infarct volume [26-29], as well as the functional outcome and mortality of stroke patients [27, 30-35], effectively promoting NF-L as a diagnostic and prognostic biomarker.

This perspective is supported by several preclinical studies demonstrating robust affections of NF-L in diverse models of acute traumatic brain injury (TBI) and stroke as indicated by an altered NF-L-related immunofluorescence intensity in histological sections as well as decreased protein levels in the infarcted tissue $[13,20,23,36]$. Especially the use of certain polyclonal antibodies not only detects the $68 \mathrm{kDa}$ NF-L protein, but also its degradation products of smaller molecular weight allow a clear-cut detection of the ischemia-affected areas and affected neurons as indicated by an increased NFL-related immunofluorescence intensity [20].

Another ischemia-sensitive component of the neuronal cytoskeleton is the microtubule-associated protein 2 (MAP2), which is predominantly expressed in dendrites [37-39]. Alterations of MAP2 expression and immunoreactivity were regularly observed in models of permanent focal cerebral ischemia [12, 40-42], but data on the effect of an acute vessel recanalization are missing. Furthermore, even though a preclinical stroke study could show an increase of MAP2 in the serum of animal subjected to ischemia [43], the conceivable use of MAP2 as a biomarker in the clinical setting has not yet been addressed.

To evaluate the potential of the cytoskeletal elements MAP2 and NF-L as possible neuroprotective targets, the present study was set up to investigate both proteins in a translational approach with multimodal characterizations. Immunofluorescence microscopy and Western blot analyses were correlated with ultrastructural and mechanical analyses using electron microscopy and atomic force microscopy in different animal models of stroke. In addition to models with permanent occlusion, mechanical and pharmacological recanalizing techniques were also used to mimic the clinical setting. Further, the possible use of MAP2 as a biomarker was assessed in direct comparison to NF-L in the serum of patients suffering from focal cerebral ischemia with and without recanalizing treatments.

\section{Material and Methods}

\section{Study Design}

This study includes preclinical and clinical data and considers modern techniques for acute vessel recanalization in both the animal experiments and the clinical investigations. First, mouse and rat brains were subjected to different types of focal cerebral ischemia in order to analyze cytoskeletal alterations using immunofluorescence microscopy, Western blotting, electron microscopy, and atomic force microscopy. Second, NF-L and MAP2 levels were measured in blood samples from patients suffering from different types of focal cerebral ischemia.

\section{Animal Experiments}

Animal experiments included the filament-based model in 64 male C57BL/6 J mice and the thromboembolic model in 12 male Wistar rats, both leading to right-sided focal cerebral ischemia due to an occlusion of the middle cerebral artery (MCAO; details are given below). Animals were provided by Charles River Laboratories (Sulzfeld, Germany) with a mean body weight of $25 \mathrm{~g}$ (mice) and $290 \mathrm{~g}$ (rats). Both models were used to induce either permanent ischemia (pMCAO) or 60 min of transient ischemia (tMCAO) with observation periods of 4 and $24 \mathrm{~h}$ in mice and rats as well as $72 \mathrm{~h}$ in mice. While the middle cerebral artery of $4 \mathrm{~h}, 24 \mathrm{~h}$, and $72 \mathrm{~h}$ pMCAO animals remained occluded for the given observation times, $4 \mathrm{~h}, 24 \mathrm{~h}$, and $72 \mathrm{~h}$ tMCAO animals underwent either mechanical (mice) or pharmacological recanalization (rats) after an ischemic period of $60 \mathrm{~min}$ (details are given below). The different models are abbreviated as follows: "h" refers to the observation time, while " $t / p$ " refers to the applied model (transient/permanent MCAO). Sufficient MCAOrelated cerebral infarction was evaluated according to the standardized scoring system by Menzies et al. [44], whereas animals had to reach a minimum of 2 (decreased grip of the contralateral forelimb while tail pulled) as pre-defined study inclusion criterion.

\section{Ischemia Induction in Animals}

MCAO surgery was performed under deep anesthesia using $2-2.5 \%$ isoflurane (Baxter, Unterschleißheim, Germany) in a mixture of $70 \% \mathrm{~N}_{2} \mathrm{O} / 30 \% \mathrm{O}_{2}$. In mice, $\mathrm{MCAO}$ was induced according to Longa et al. [45], with minor modifications as 
described before in detail [46]. In short, a standardized siliconcoated 6-0 filament (Doccol Corporation, Redlands, CA, USA) was inserted into the internal carotid artery and carefully moved forward to the origin of the middle cerebral artery until bending was observed or resistance felt. In rats, MCAO surgery was performed according to Zhang et al. [47], with minor modifications as described earlier [48]. In brief, a weight-adapted blood clot was prepared and later injected in the distal section of the internal carotid artery using a PE-50 catheter and a small bolus of saline. Every procedure during anesthesia was performed using a rectal probe and a thermostatically controlled warming pad adjusting the body temperature to $37^{\circ} \mathrm{C}$. In order to mimic recanalizing approaches such as intravenous thrombolysis and mechanical thrombectomy as routinely applied in the clinical setting, transient MCAO (tMCAO) was accomplished by either filament removal in mice or intravenous administration of recombinant tissue plasminogen activator (rtPA, Actilyse ${ }^{\circledR}$, Boehringer Ingelheim, Ingelheim am Rhein, Germany) in rats $60 \mathrm{~min}$ after ischemia induction, whereas animals with permanent ischemia (pMCAO) remained untreated.

\section{Fluorescence Microscopy}

Animals were sacrificed and transcardially perfused with saline and 4\% paraformaldehyde (PFA; Serva, Heidelberg, Germany) in phosphate-buffered saline (PBS) at pre-defined observation periods of 4,24 , and $72 \mathrm{~h}$. Brains were removed from the skull and post-fixed in $4 \%$ PFA for $24 \mathrm{~h}$, followed by equilibration in $30 \%$ phosphate-buffered sucrose. Forebrains were then serially cut into coronal $30-\mu \mathrm{m}$-thick sections with a freezing microtome (Leica SM 2000R, Leica Microsystems, Wetzlar, Germany). All brain sections were stored at $4^{\circ} \mathrm{C}$ in $0.1 \mathrm{M}$ Tris-buffered saline, $\mathrm{pH} 7.4$ (TBS), containing $0.2 \%$ sodium azide. For multiple immunofluorescence labeling, sections were blocked with 5\% normal donkey serum and $0.3 \%$ Triton X-100 in TBS for $1 \mathrm{~h}$ and then incubated overnight with primary antibodies (Table 1) diluted in the blocking solution. The next day, sections were incubated with mixtures of appropriate secondary antibodies (Table 1 ) in TBS containing $2 \%$ bovine serum albumin for $1 \mathrm{~h}$ at room temperature. Every change of incubation medium was preluded and followed by thorough rinsing in TBS. Finally, sections were mounted onto fluorescence-free microscope slides and cover-slipped with fluorescence mounting medium (Dako North America, Inc., Carpinteria, CA, USA). Omitting primary antibodies served as control, which resulted in the absence of staining. Microscopy and image acquisition of qualitative MAP2/NFL data were performed with the Biorevo BZ-9000 microscope (Keyence, Neu-Isenburg, Germany).

Sample sizes used for immunofluorescence microscopy are as follows: mice, 4h-t (n=5), 4h-p (n=6), 24h-t (n=6), 24h-p (n=6), 72h-t ( $n=6)$, and 72h-p ( $n=2)$; rats, 4h-t ( $n=3)$, 4h-p $(n=4) ; 24 \mathrm{~h}-\mathrm{t}(n=3)$, and $24 \mathrm{~h}-\mathrm{p}(n=2)$.

\section{Fluorescence Intensity Measurements}

For quantification of fluorescence intensities, NF-L- and MAP2-labeled brain sections were scanned with an Axio Scan.Z1 slide scanner (Carl Zeiss Microscopy GmbH, Jena, Germany), and files were analyzed using the netScope Viewer Pro software (Net-Base Software GmbH, Freiburg i. Br., Germany). Two different quantifications were performed:

(a) Corresponding to data shown in Fig. 2: Images of striatal and cortical regions in mice after $4 \mathrm{~h}-\mathrm{t}, 4 \mathrm{~h}-\mathrm{p}, 24 \mathrm{~h}-\mathrm{t}$, 24h-p, 72h-t, and 72h-p were captured at $10 \times$ magnification. Due to the slightly variable distribution of the ischemic lesion after MCAO [49], sections and regions of interest (ROIs) were selected based on the ischemia-induced decrease of MAP2related immunofluorescence intensity. They were then mirrored to the contralateral hemisphere which served as control, thus capturing 4 ROIs per animal. In one 72h-p mouse brain, poor tissue integrity impeded quantification of the cortex, leading to a sample size of $72 \mathrm{~h}-\mathrm{p}$ : cortex, $n=1$, and striatum $n=2$, only.

(b) Corresponding to data shown in Fig. 3: To assess possible region-dependent alterations of immunofluorescence intensities, 9 ROIs were placed from non-affected medial to affected lateral regions throughout the cortex of the ischemic hemisphere of 24h-t and 24h-p mice. Thereby, ROIs 4 and 5 were strictly placed next to the ischemic border. Thus, ROIs 1-4 were always placed in non-ischemic and ROIs 5-9 in ischemic areas. On the contralateral hemisphere, 3 ROIs were mirrored to corresponding regions and served as control. To capture the immunofluorescence intensity throughout all cortical layers, each ROI had a field dimension of $200 \mu \mathrm{m}$ width and a height which was adapted to the height of the cortex at each point. Per animal and ROI, the mean fluorescence intensity of each ROI was measured using ImageJ software (National Institutes of Health, Bethesda, MD, USA) to calculate the $n$-fold change compared to the mean value of the 3 contralateral ROIs, which served as control.

\section{Western Blots}

Mice were sacrificed and perfused with saline, only. Brains were removed from the skull and manually dissected. Next, stroke-affected areas, being demarked by the ischemiaassociated edema, as well as the respective contralateral areas were dissected, snap-frozen in liquid nitrogen, and stored at $-80^{\circ} \mathrm{C}$. Each sample was homogenized and lysed by ultrasonification in $60 \mathrm{mM}$ Tris- $\mathrm{HCl}, \mathrm{pH} 6.8$, containing $2 \%$ sodium dodecyl sulfate (SDS), $10 \%$ sucrose, and a protease inhibitor cocktail (Cell Signaling, Leiden, The Netherlands) on ice. Next, probes were centrifuged at $13,000 \mathrm{rpm}$ and $4^{\circ} \mathrm{C}$ 
Table 1 Antibodies used for immunohistochemistry and Western blot

\begin{tabular}{lll}
\hline & Dilution & Manufacturer \\
\hline Immunohistochemistry & & \\
Primary antibody & & \\
$\quad$ Mouse-anti-MAP2 (clone HM-2) & $1: 500$ & Sigma, Taufkirchen, Germany \\
$\quad$ Rabbit-anti-neurofilament L & $1: 200$ & Synaptic Systems, Göttingen, Germany \\
Secondary antibody & Dilution & Manufacturer \\
AlexaFluor488-donkey-anti-mouse IgG & $1: 250$ & Thermo Fisher, Waltham, MA, USA \\
AlexaFluor568-donkey-anti-rabbit IgG & $1: 250$ & Thermo Fisher \\
& & \\
Western blot & & \\
Primary antibody & & \\
$\quad$ Mouse-anti-neurofilament L (clone DA2) & $1: 1000$ & Thermo Fisher \\
Rabbit-anti-neurofilament L & $1: 2000$ & Synaptic Systems \\
$\quad$ Mouse-anti-MAP2 (clone HM-2) & $1: 1000$ & Sigma \\
$\quad$ Mouse-anti- $\beta$-actin & $1: 2000$ & Cell Signaling, Danvers, MA, USA \\
Secondary antibody & Dilution & Manufacturer \\
HRP-horse-anti-mouse IgG & $1: 10000$ & Vector lab., Burlingame, CA, USA \\
HRP-goat-anti-rabbit IgG & $1: 10000$ & Vector lab. \\
\hline
\end{tabular}

for $10 \mathrm{~min}$, followed by protein concentration measurements using the BCA kit (Thermo Fisher, Waltham, MA, USA). Proteins were denatured in sample buffer $(250 \mathrm{mM}$ Tris$\mathrm{HCl}, \mathrm{pH} 6.8$, containing 4\% SDS, $10 \%$ glycerol, and $2 \% \beta-$ mercaptoethanol) at $95^{\circ} \mathrm{C}$ for $5 \mathrm{~min}$. Then, proteins were separated using a $12.5 \%$ SDS-PAGE and transferred to nitrocellulose membranes (Th.Geyer, Renningen, Germany). Membranes were blocked with $5 \%$ dry milk in TBS $(50 \mathrm{mM}$ Tris- $\mathrm{HCl}, 150 \mathrm{mM} \mathrm{NaCl}, \mathrm{pH} 7.5$ ) for $30 \mathrm{~min}$ and incubated with primary antibodies (Table 1 ) at $4{ }^{\circ} \mathrm{C}$ overnight. After thorough washing in buffer $(6 \mathrm{~g} / 1$ Tris, $8.8 \mathrm{~g} / 1 \mathrm{NaCl}, 3 \mathrm{ml} / \mathrm{l}$ Tween 20), horseradish peroxidase-conjugated secondary antibodies (Table 1) were added for $1 \mathrm{~h}$, and membranes were developed with the ECL kit (Thermo Fisher). After image acquisition, membranes were stripped with stripping buffer (15 g/l glycine, $1 \mathrm{~g} / 1 \mathrm{SDS}, 10 \mathrm{ml} / 1$ Tween 20, $\mathrm{pH} 2.2$ ) and reused to detect $\beta$-actin as housekeeping protein for reference. The relative protein concentration of MAP2 and NF-L was calculated from the respective $\beta$-actin-related chemiluminescence intensity. Sample sizes for Western blot analyses were 4h-t $(n=5), 4 h-p(n=6), 24 h-t(n=6)$, and 24h-p $(n=5)$.

\section{Electron Microscopy}

Mice were sacrificed and transcardially perfused with saline, followed by perfusion with $4 \%$ PFA and $0.5 \%$ glutaraldehyde in PBS. After removal from the skull, brains were post-fixed in the same fixative for $24 \mathrm{~h}$. Then, brains were cut into $60-\mu \mathrm{m}-$ thick coronal sections using a vibratome (Leica Microsystems, Wetzlar, Germany) in cooled PBS. Sections were then transferred into PBS and stained with $0.5 \%$ osmium tetroxide
(EMS, Hatfield, PA, USA) for $30 \mathrm{~min}$, followed by dehydration in graded ethanol and another staining step with $1 \%$ uranyl acetate (Serva) in $70 \%$ ethanol for $1 \mathrm{~h}$. Sections were further dehydrated in ethanol and propylene oxide (Sigma Aldrich, Steinheim, Germany) and then incubated in Durcupan (Sigma Aldrich). After embedding between coated microscope slides and cover slips, the Durcupan-saturated sections were polymerized at $56^{\circ} \mathrm{C}$ for $48 \mathrm{~h}$. Areas showing stroke-associated edema were identified by light microscopy and transferred onto blocks of resin for a second polymerization step. The blocks were trimmed and cut into 55-nm-thick ultra-thin sections using an ultra-microtome (Leica Microsystems). Finally, the sections were transferred on formvar-coated grids and stained with lead citrate for $6 \mathrm{~min}$. Ultrastructural analysis was performed using a Zeiss SIGMA electron microscope (Carl Zeiss Microscopy GmbH, Oberkochen, Germany).

In ischemia-affected cortical regions, the neurofilament density was analyzed in cross sections of myelinated axons. For this purpose, detectable neurofilaments were identified by diameter and morphology and counted, and the area of the cross-sectioned axon was measured to calculate the neurofilament density per $\mu \mathrm{m}^{2}$. Measurements thereby included 5 different fields of view from ischemiaaffected cortical areas per animal, which were calculated as mean values and compared with contralateral unaffected regions. Of note, as a proper distinction of neurofilaments is impeded in tangentially cross-sectioned axons, the analysis was restricted to proper cross sections, while cytoplasmic areas showing organelles such as mitochondria were also excluded. Sample sizes for electron microscopy were: $4 \mathrm{~h}-\mathrm{t}$ and $24 \mathrm{~h}-\mathrm{t}$ ( $n=5$, each). 


\section{Atomic Force Microscopy}

To demonstrate alterations of mechanical properties within ischemia-affected regions, atomic force microscopy (AFM) was performed in a mouse $24 \mathrm{~h}$ after pMCAO (24h-p). To enable the detection of ischemia-affected regions, fluorescein isothiocyanate-conjugated albumin (FITC-albumin, $0.2 \mathrm{mg}$ dissolved in $0.1 \mathrm{ml}$ saline, Sigma, Taufkirchen, Germany) was intravenously applied to demarcate areas of ischemia-associated blood-brain barrier (BBB) breakdown $23 \mathrm{~h}$ after ischemia induction [50]. After a circulation time of $1 \mathrm{~h}$, the brain was removed from the skull and immediately cut into $350-\mu \mathrm{m}$-thick slices using a vibratome (HM $650 \mathrm{~V}$, ThermoFisher Scientific, Walldorf, Germany) in artificial cerebrospinal fluid (ACSF, containing $2.5 \mathrm{mM} \mathrm{KCl}$, $260 \mathrm{mM}$ D-Glucose, $26 \mathrm{mM} \mathrm{NaHCO}_{3}, 1.25 \mathrm{mM} \mathrm{NaH}_{2} \mathrm{PO}_{4}$, $2 \mathrm{mM}$ Na-pyruvate, $3 \mathrm{mM}$ myo-inositol, $0.4 \mathrm{mM}$ ascorbic acid, $1 \mathrm{mM} \mathrm{MgCl}$, $2 \mathrm{mM} \mathrm{CaCl}_{2}, 20 \mathrm{mM}$ Hepes, $\mathrm{pH}$ 7.4). Subsequently, slices were glued (Histroacryl, Braun, Melsungen, Germany) onto microscope slides followed by measurement of the elastic strength (Young's modulus) in the ischemia-affected and contralateral cortex. The AFM used is a NanoWizard 4 with $300 \mu \mathrm{m}$ HybridStage (JPK, Berlin, Germany) combined with an Axio Zoom.V16 (Zeiss, Oberkochen, Germany) for fluorescence imaging [51]. The AFM image and optical image are recorded in a common reference system using the AFM software calibration routine. A CONT (Nanoworld, Neuchâtel, Switzerland) contact mode cantilever (spring constant $213 \mathrm{mN} / \mathrm{m}$ ) was modified with a 6 - $\mu \mathrm{m}$-diameter polystyrene bead to increase contact area. Force ramps were recorded with the following parameters: maximum force $7.5 \mathrm{nN}$, zspeed $20 \mu \mathrm{m} / \mathrm{s}$, z-length $30 \mu \mathrm{m}, 2048 \mathrm{~Hz}$ capture rate, and $10 \mu \mathrm{m}$ data point spacing (Suppl. Figure 1 A \& B). AFM data was first analyzed with the JPK data processing software to calculate the Young's modulus using a Hertz fit to the smoothed and baseline corrected forceindentation curves (Suppl. Figure 1C). Data was postprocessed with a custom written Matlab program (MathWorks, Natick, MA, USA) to calculate local averages and construct the overlay of AFM data with the whole-slice overview shown in Fig. 6. In the ischemia-affected cortex, the elastic strength of the tissue was recorded over a distance of approximately $1100 \mu \mathrm{m}$ starting from the area of evident FITC-albumin extravasation across the border zone of detectable FITC-albumin extravasation, which delineates the infarcted tissue [52-54]. Mean values of 11 positions were calculated, with each position measuring $100 \times 100 \mu \mathrm{m}$ and consisting of 100 single measurements. In the contralateral cortex, 3 different positions (total 300 data points) served as control. During the whole procedure, the coronal brain slices were kept submerged in ACSF to prevent dehydration. Sample size is $24 \mathrm{~h}-\mathrm{p}(n=1)$.

\section{Blood Sampling in Patients Suffering from Focal Cerebral Ischemia}

In a prospective, non-interventional study, a total of 81 patients, hospitalized at the stroke unit of the Department of Neurology, Leipzig University, were included. Blood samples were collected at two pre-defined time points: 12-24 h ("day 1") and 3-5 days ("day 3") after hospital admission. Main inclusion criteria were (a) ischemic stroke, defined by a sudden onset of a focal neurological deficit independent of the vascular territory with evidence of a cerebral infarction either on computed tomography or magnetic resonance tomography, and (b) transient ischemic attack (TIA) with a naturally lacking evidence for a cerebral infarction on radiological examination [55]. Main exclusion criteria were any kind of known other cerebral pathologies such as neurodegenerative or inflammatory disorders as well as intracerebral hemorrhage. Patients were categorized for (a) "TIA," (b) "stroke," and (c) "stroke with intervention," which represent patients who underwent a therapy aiming to re-establish cerebral blood flow (i.e., intravenous thrombolysis and/or mechanical thrombectomy). Furthermore, imaging data were used to categorize for (a) "lacunar infarcts" (diameter $\leq 1.5 \mathrm{~cm}$ ) and (b) "larger infarcts" (diameter $>1.5 \mathrm{~cm}$ ). For descriptive analyses, additional data were recorded concerning the severity of the neurological deficit (National Institute of Health Stroke Scale, NIHSS) at hospital admission as well as the individual infarct etiology and medical history.

\section{Enzyme-Linked Immunosorbent Assay (ELISA)}

Human blood samples were allowed to coagulate for $1 \mathrm{~h}$ at room temperature and then centrifuged at $3500 \times \mathrm{g}$ for $10 \mathrm{~min}$. Thereafter, the supernatant was aliquoted and stored at $-80^{\circ} \mathrm{C}$ until further processing. Serum protein levels were measured using commercial ELISA kits from Abbexa (Cambridge Science Park, Cambridge, United Kingdom; NF-L, Cat.\# abx258398; MAP2, Cat.\# abx358608). Analyses were performed according to the instructions given by the manufacturer. The optical density (OD) was measured at $450 \mathrm{~nm}$ using a Mithras LB940 microplate reader (Berthold Technologies, Bad Wildbad, Germany), and then protein concentrations were calculated by extrapolation of the linear portion of the standard curve. The following sample sizes were achieved: TIA, MAP2 $(n=12)$ and NF-L $(n=12)$; stroke, MAP2 $(n=26)$ and NF-L $(n=27)$; stroke with intervention, MAP2 $(n=21)$ and NF-L $(n=20)$; lacunar infarct, MAP2 $(n=17)$ and NF-L $(n=16)$; and larger infarct, MAP2 $(n=29)$ and NF-L $(n=30)$.

\section{Statistical Analyses}

Data analysis was performed using Graph Pad Prism 5.01v (GraphPad Software Inc., La Jolla, CA, USA) and the SPSS 
software package version 25 (IBM SPSS Statistics for Windows, IBM Corp., Armonk, NY, USA). The Grubbs' or ROUT test was used to check for statistical outliers, and the Kolmogorov-Smirnov test (SigmaStat; v3.10, San Jose, CA, USA) was used to check for normal distribution of the data. After confirmation of a normal distribution, ANOVA followed by Bonferroni's multiple comparison post hoc test was used to check for statistically significant differences between three or more groups. Non-normally distributed data of two dependent groups were analyzed with the Wilcoxon signed-rank test, while two independent groups were analyzed using the non-parametric Mann-Whitney U test. Non-normally distributed data of three or more independent groups were analyzed using the Kruskal-Wallis test followed by Dunn's multiple comparison post hoc test. For analysis of the human serum samples, the potentially confounding factors age and hypertension were ruled out by additional calculations (not shown). In general, with the significance level $\alpha=0.05, p<0.05$, indicated statistically significant differences.

\section{Results}

\section{MAP2-Related Immunofluorescence Intensity Shows Early and Long-Lasting Reductions, While NF-L- Related Immunofluorescence Intensity Is Increased Throughout Later Time Points}

Although MAP2 and NF-L have particularly proven as ischemia-sensitive elements of the neuronal cytoskeleton in various studies [13, 20, 23, 36, 40, 41, 56], a simultaneous region- and time-dependent characterization among different models of focal cerebral ischemia is not yet available. Therefore, immunofluorescence labeling of NF-L and MAP2 was performed throughout the applied models and time points. Of note, ischemia-associated alterations are comprehensively indicated by changes of NF-L- and MAP2related immunofluorescence intensity throughout the applied models in mice (Fig. 1). While the ischemic region is regularly characterized by a decreased MAP2-related immunofluorescence intensity, the NF-L-related immunofluorescence intensity appears to be increased 24 and $72 \mathrm{~h}$ after ischemia induction. However, only a discontinuous reduction of the MAP2related immunofluorescence intensity is observed after $4 \mathrm{~h}$ of transient ischemia with no apparent increase of the NF-Lrelated immunofluorescence intensity in the ischemic region. The latter becomes increasingly detectable after $4 \mathrm{~h}$ of permanent ischemia and later time points, which is then accompanied with a widespread and continuous reduction of the MAP2-related immunofluorescence intensity (Fig. 1).

Similar alterations of immunoreactivity were observed for the translationally relevant thromboembolic model of MCAO in rats 4 and $24 \mathrm{~h}$ after permanent and transient ischemia, the latter following pharmacological recanalization (Suppl. Figure 2). In each model, the MAP2-related immunofluorescence intensity was diminished in the ischemic region, whereas the NF-L-related immunofluorescence intensity was increased in the same area.

By quantification of the MAP2- and NF-L-related immunofluorescence intensities (Fig. 2) in the applied mouse models, the reduction of MAP2-related immunofluorescence intensity in stroke tissue was found to be significant after 4h-p, 24h-t, 24h-p, and 72h-t compared to control regions. In addition, the MAP2-related immunofluorescence intensity appeared to be significantly lower after $72 \mathrm{~h}-\mathrm{t}$ compared to $4 \mathrm{~h}-\mathrm{t}$ and 24h-t. Numerically, the MAP2-related immunofluorescence intensity of 72h-p infarct tissue decreased just as much (72h-p cortex, 0.541 [arbitrary unit, aU]; 72h-p striatum, 0.581 [aU]) but represented sample sizes of $n=1$ (cortex) and $n=2$ (striatum), only. Consequentially, cortical $72 \mathrm{~h}-\mathrm{p}$ data was not considered for statistical analysis.

The increase of the NF-L-related immunofluorescence intensity was not yet significant after $4 \mathrm{~h}-\mathrm{t}$ and $4 \mathrm{~h}-\mathrm{p}$ but increased progressively at later time points. Hence, NF-L-related immunofluorescence intensity was significantly higher in ischemic areas compared to the contralateral hemisphere after $24 \mathrm{~h}-\mathrm{t}$, 24h-p, 72h-t, and 72h-p. The increase of the NF-L-related immunofluorescence intensity from early to late time points even proved to be significantly different between each time point, with the exception of $24 \mathrm{~h}-\mathrm{p}$ to $72 \mathrm{~h}-\mathrm{p}$. Interestingly, neither the MAP2- nor the NF-L-related immunofluorescence intensity differed significantly between transient and permanent ischemia (4h-t vs. 4h-p; 24h-t vs. 24h-p; 72h-t vs. 72h-p) (Fig. 2).

\section{Alterations of MAP2-Related Immunofluorescence Intensity Are Uniformly Apparent Throughout the Ischemic Area, While Alterations of NF-L-Related Immunofluorescence Intensity Are Regionally Different}

After showing time-dependent alterations of NF-L and MAP2, further analyses addressed possible region- or reperfusion-specific differences. Therefore, multiple ROIs were placed throughout the cortex of $24 \mathrm{~h}-\mathrm{t}$ and $24 \mathrm{~h}-\mathrm{p}$ mice (Fig. 3a). Here, fluorescence intensity measurements (Fig. $3 \mathrm{~b}$ and c) showed an abrupt and significant decrease of the MAP2-related immunofluorescence intensity at the infarct border (ROI 4 to ROI $5 ; 24 \mathrm{~h}-\mathrm{t}$ ), thereby coinciding with an increase of the NF-L fluorescence intensity which became significant at ROIs 6 and 7 (24h-t and 24h-p). Furthermore, the MAP2-related immunofluorescence intensity was significantly altered in each ROI within the ischemic area, whereas alterations of NF-L-related immunofluorescence intensity were only significant in the somatosensory cortex 
Fig. 1 Immunofluorescence labeling of MAP2 and NF-L at different time points in the mouse model of MCAO: the reduction of MAP2-related immunoreactivity (green) identifies the infarct border (dashed line) in the cortex of mice at all time points of transient and permanent ischemia. The NF-L-related

immunoreactivity (red) is increased in the infarct area, with a clear increase after $24 \mathrm{~h}$ and $72 \mathrm{~h}$, but no apparent increase after $4 \mathrm{~h}-$ t. Scale bars: $200 \mu \mathrm{m}$

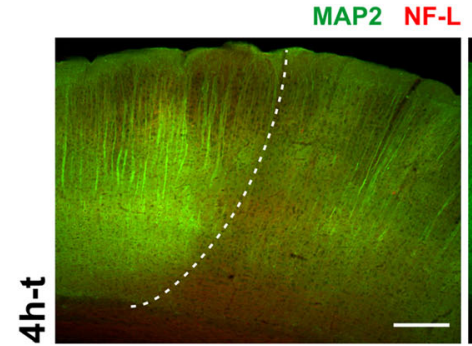

MAP2

NF-L
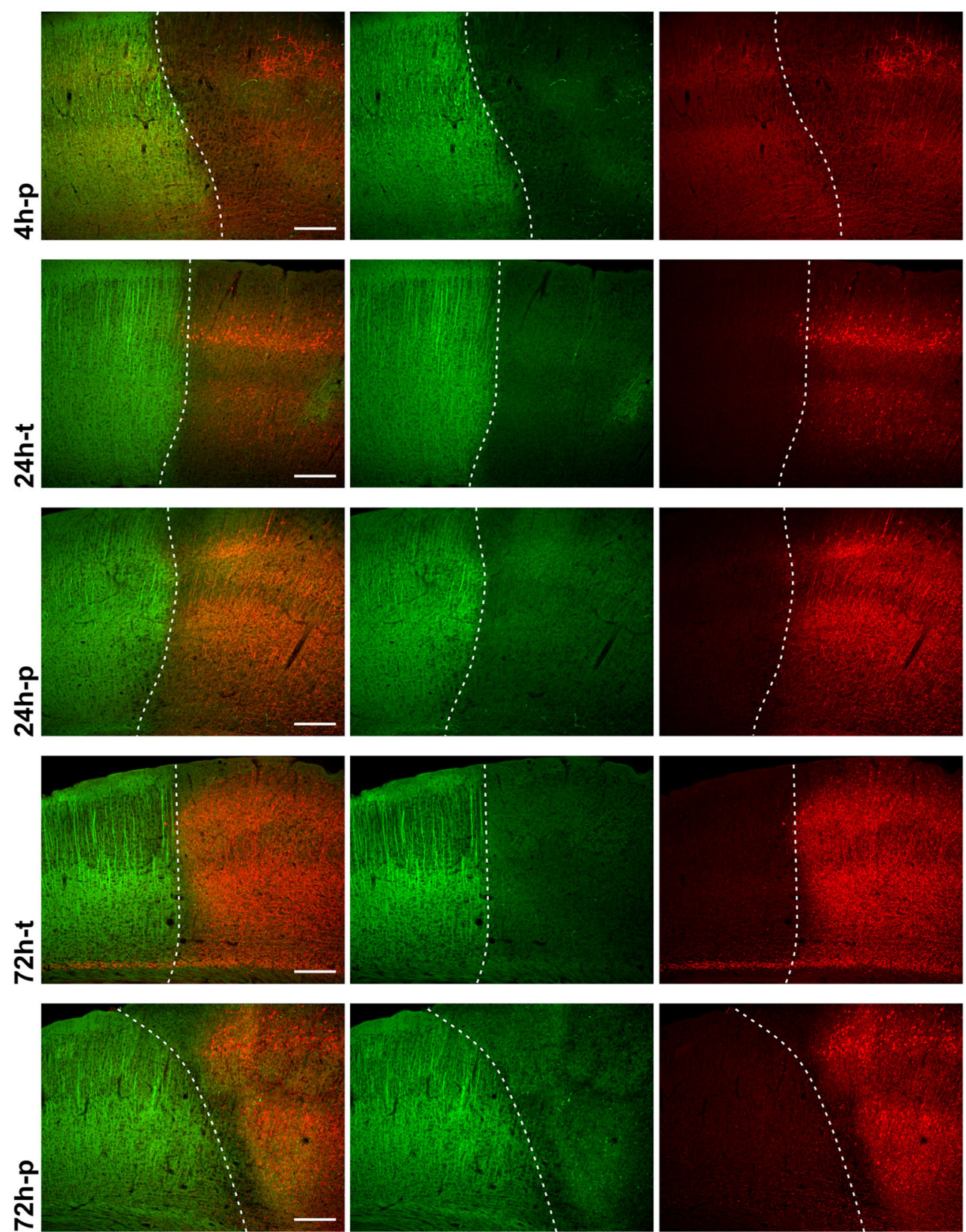

(ROIs 6 and 7). Of note, a detrimental effect of the recanalizing approach was not observed as neither MAP2nor NF-L-related immunofluorescence intensities differed significantly when comparing transient and permanent ischemia (24h-t and 24h-p).

\section{Decrease of MAP2 Protein and NF-L Protein Degradation in Stroke Tissue}

Next, we performed Western blot analyses using 4h-t, 4h-p, $24 \mathrm{~h}-\mathrm{t}$, and 24h-p mouse tissue to investigate whether the 


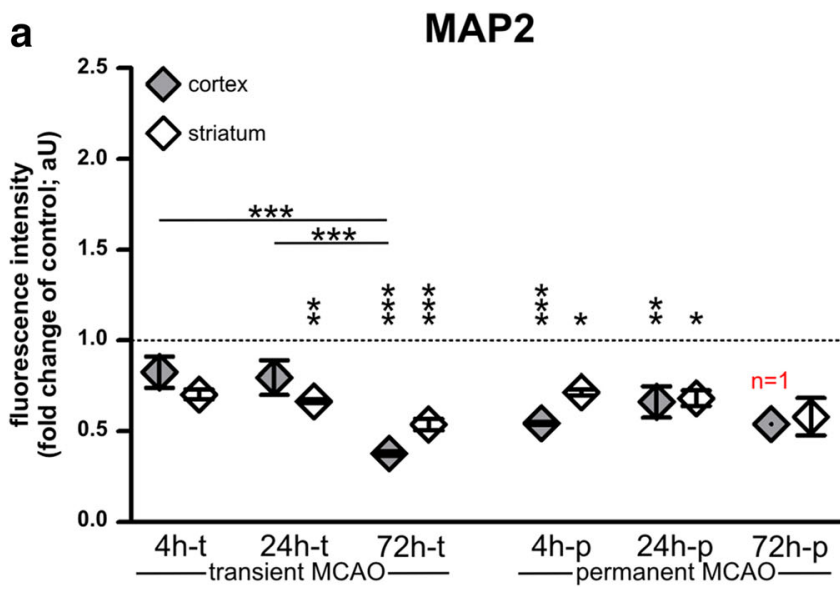

Fig. 2 a The fluorescence intensity of MAP2 is regularly reduced, including early time points, but did not reach statistical significance after $4 \mathrm{~h}$ of transient ischemia. b NF-L-related fluorescence intensities in the infarct area are significantly and progressively increased, but not yet

abovementioned alterations are reflected by changes of the MAP2 and NF-L protein levels in ischemic brain tissue. Western blots were also used to determine the abundance of NF-L degradation products, which are held responsible for the increase of NF-L-related immunoreactivity in ischemic brain tissue [20]. Importantly, in line with the decreased MAP2related immunofluorescence intensity observed in histological sections, Western blot analyses confirm decreased MAP2 protein levels in ischemia-affected tissue for each investigated time point (Fig. 4a and b), although not reaching statistical significance.

Using two different NF-L antibodies, a trend toward reduced NF-L protein levels was observed after 4 and $24 \mathrm{~h}$ of permanent ischemia (Fig. 4c and d), while the transient model only exhibited a comparable reduction of NF-L protein levels in striatal areas of $24 \mathrm{~h}-\mathrm{t}$ animals using the polyclonal antibody, however, failing statistical significance. Of note, selective analysis of NF-L degradation products ( $40-65 \mathrm{kDa})$ revealed a significant increase in the ischemic cortex after $24 \mathrm{~h}$ of permanent ischemia (Fig. 4e and f). Here, a 3.38-fold increase of NF-L degradation products was measured compared to controls, which also reached significance compared to cortical MCAO tissue of 4h-p and 24h-t animals.

\section{Ultrastructural Analysis Confirms Cytoskeletal Alterations in Ischemia-Affected Areas}

To investigate whether the described alterations of cytoskeletal proteins are also reflected at an ultrastructural level, we applied electron microscopy of ischemiaaffected cortical regions and contralateral non-affected areas of $4 \mathrm{~h}-\mathrm{t}$ and $24 \mathrm{~h}-\mathrm{t}$ animals. To allow a proper differentiation of neurofilaments from other components of the axonal cytoplasm, the analysis was restricted to axons

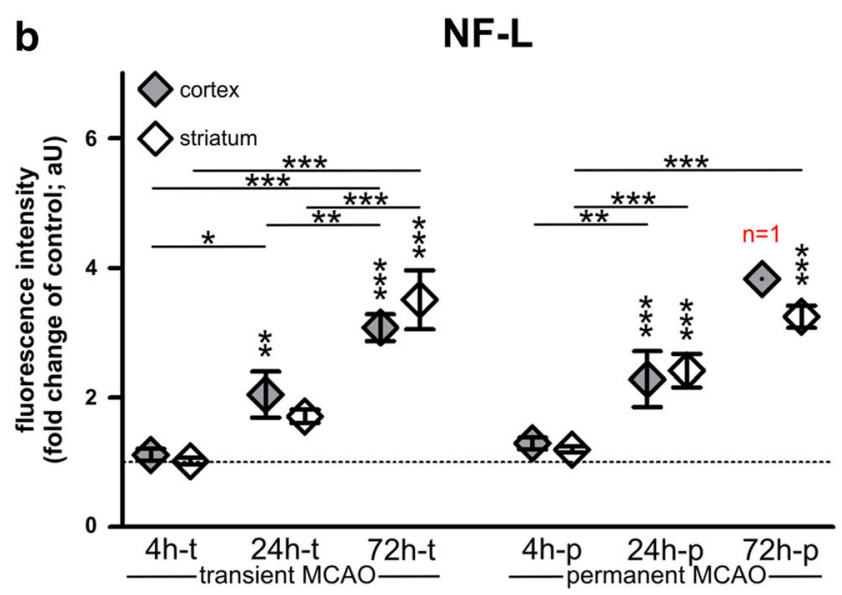

after $4 \mathrm{~h}$ of transient or permanent ischemia. Sample sizes: each group, $n=5-6$; except for $72 \mathrm{~h}-\mathrm{p}: n=1-2$. Data are presented as mean values; error bars indicate the standard error. ${ }^{*} p<0.05, * * p<0.01, * * * p<0.001$

showing strictly transversally sectioned neurofilaments, only. Here, the detectable neurofilaments were counted to calculate the neurofilament density per $\mu \mathrm{m}^{2}$. Of note, axons in ischemia-affected cortical areas regularly appeared less electron dense, which is indicative of an ischemia-associated cellular edema (Fig. 5a). Here, the homogeneous distribution of neurofilaments is lost throughout the cytoplasm (Fig. 5a). Further, the density of detectable neurofilaments was significantly reduced compared to control areas in both $4 \mathrm{~h}-\mathrm{t}$ and $24 \mathrm{~h}-\mathrm{t}$ animals (Fig. 5b).

\section{Mechanical Tissue Properties Are Significantly Altered in Ischemia-Affected Tissue}

As the cytoskeleton is presumed to ensure cellular integrity and mechanical stability, we tried to determine whether the described alterations of neuronal cytoskeletal proteins are reflected by altered mechanical properties of the ischemic tissue. Therefore, acute brain slices of a $24 \mathrm{~h}-\mathrm{p}$ mouse brain were prepared in order to measure the elastic strength (Young's modulus) in ischemia-affected cortical areas and contralateral regions using atomic force microscopy. Therefore, ischemia-affected areas were identified by FITC-albumin extravasations indicative of an ischemia-associated BBB breakdown. Here, areas near to the center of the observed FITC-albumin extravasation showed a significantly decreased elastic strength compared to contralateral regions (positions $1,3,4$, and 5 in Fig. 6a and b). In contrast, peripheral border zones not showing FITC-albumin extravasation exhibited significantly increased values (positions 7-11). Of note, the measured regions correspond to regions of the previously described MAP2 and NF-L alterations. 


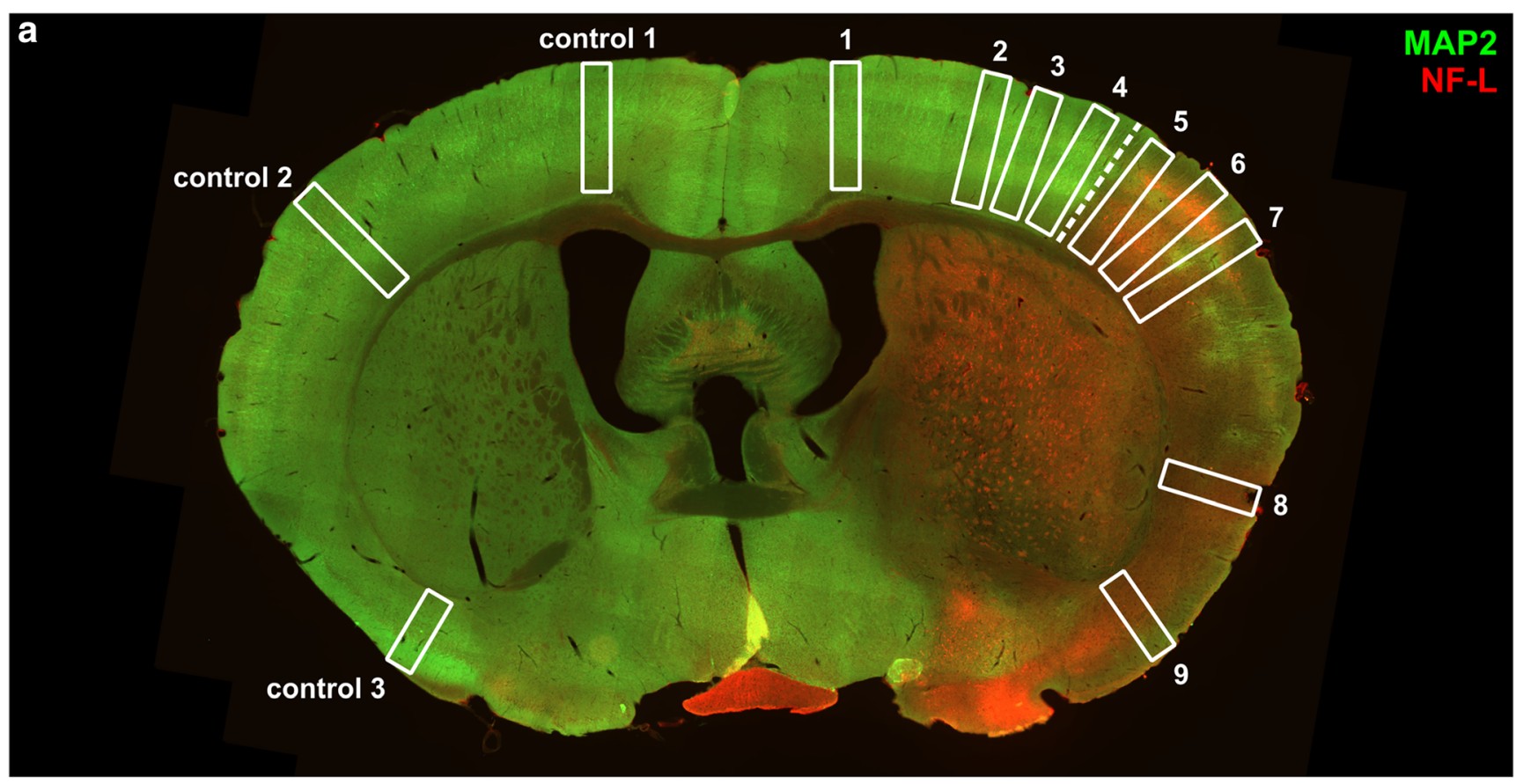

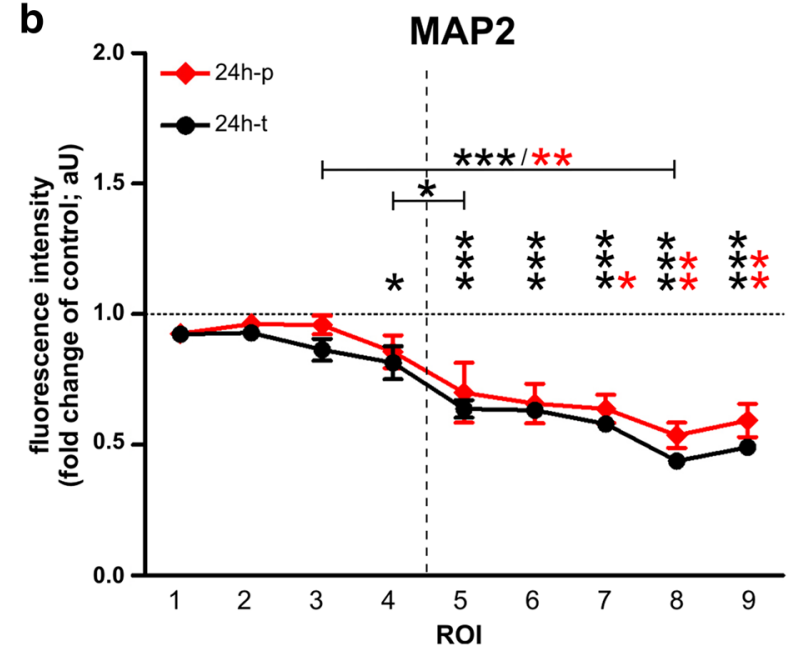

Fig. 3 a The illustration indicates regions of interest (ROIs) used for quantifications of MAP2- and NF-L-related immunofluorescence intensities after $24 \mathrm{~h}$ of transient and permanent MCAO in mice. b When compared to the contralateral hemisphere, the MAP2-related immunofluorescence intensity was significantly reduced throughout the infarcted cortex, $\mathbf{c}$ whereas the increase of NF-L-related immunoreactivity

\section{MAP2 Serum Concentrations Are Significantly Increased in Stroke Patients and Appear to Be More Sensitive to Ischemia than NF-L}

In order to determine whether the tissue-specific alterations observed in the animal models correspond to elevated serum concentrations of MAP2 and NF-L in human stroke patients, blood samples of 81 patients (Table 2) were analyzed at day 1 and day 3 after ischemia onset as indicated by the awareness of neurological symptoms. At hospital admission, patients suffering from TIA are naturally less affected when compared
C

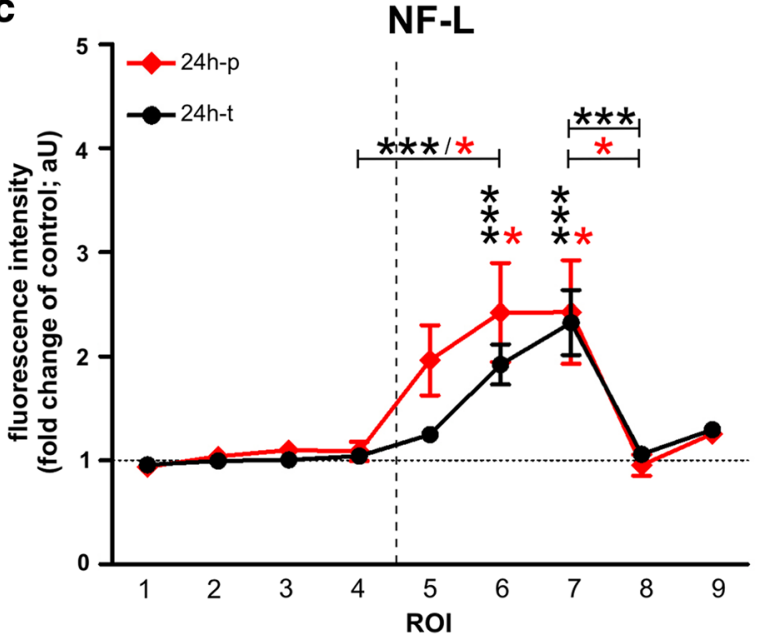

was only significant in ROIs of the somatosensory cortex. Neither MAP2nor NF-L-related immunofluorescence intensities differed significantly between transient and permanent MCAO. The dashed line represents the infarct border. Sample sizes in $\mathbf{b}$ and $\mathbf{c}: n=6$ for all ROIs. Data are presented as mean values; error bars indicate the standard error. $* p<0.05$, $* * p<0.01$, $* * * p<0.001$

to patients suffering from a stroke with or without intervention, as demonstrated by the NIHSS.

Accordingly, significantly increased MAP2 serum levels were observed when comparing TIA patients with patients suffering from stroke, with or without intervention (Fig. 7a). Moreover, patients exhibiting larger infarct sizes showed significantly elevated MAP2 serum levels, although a stepwise increase in patients with lacunar lesions was not observed (Fig. 7b). NF-L levels were found to increase numerically in patients suffering from stroke, but did not differ significantly from TIA patients (Fig. 7a). Although the increase of NF-L 


\section{a}

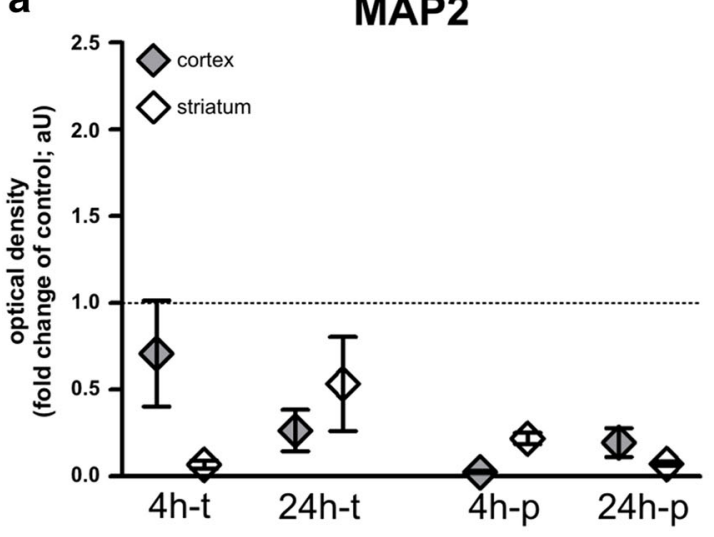

C
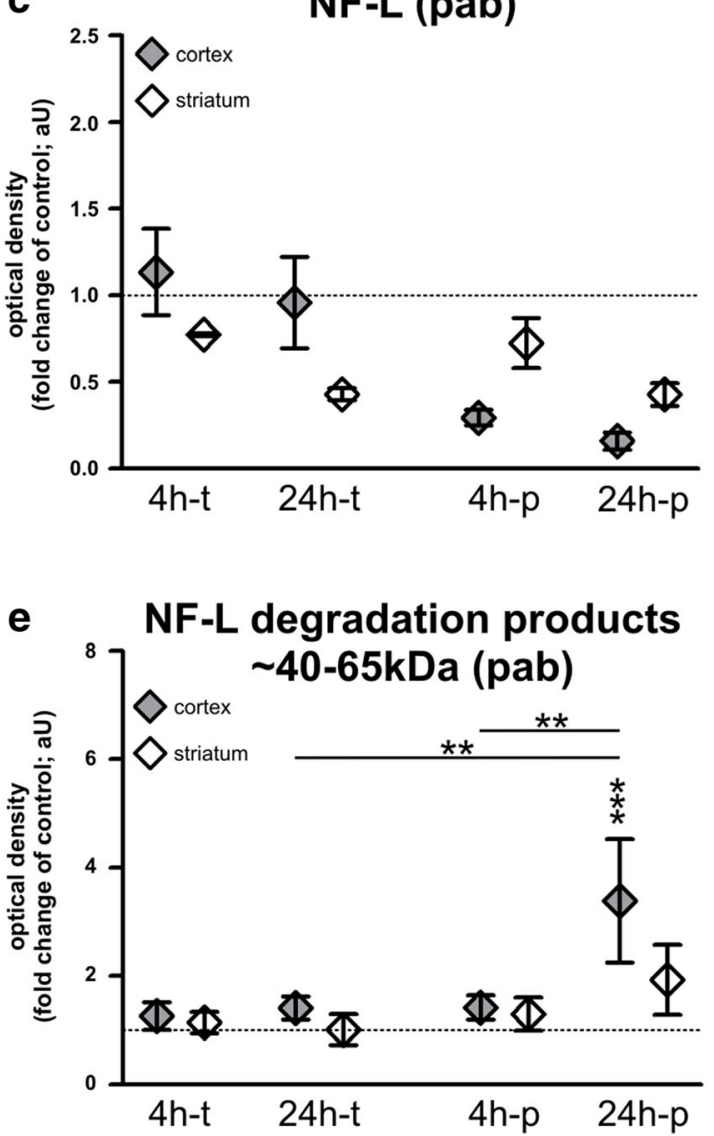

Fig. 4 a, b Western blot analyses of MAP2 and NF-L in mice after 4 and $24 \mathrm{~h}$ of transient and permanent MCAO: MAP2 levels decrease in stroke tissue throughout the applied models, although without reaching significance. c-f) Western blot was performed with a polyclonal "pab" NF-L antibody (c, e, f) and a monoclonal antibody "mab" (d). Thereby a decrease of NF-L in infarcted tissue was measured, which was most

serum levels was not found to be statistically significant, the levels numerically decreased after recanalization to levels comparable to TIA patients, while this post-interventional reduction was not observed for MAP2 levels. Further, a b

ischemia control
ctx stri stri ctx

MAP2

$250 \mathrm{kDa}$ -

$150 \mathrm{kDa}$ -

ß-actin 50kDa -

$37 \mathrm{kDa}$ -

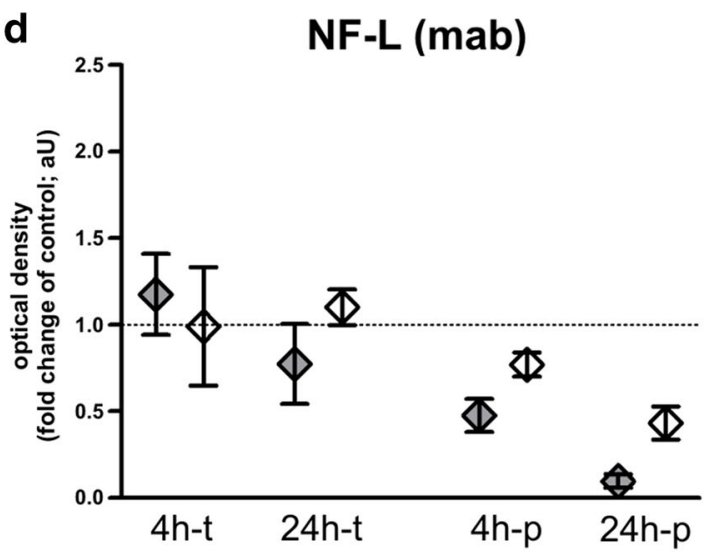

$\mathbf{f}$

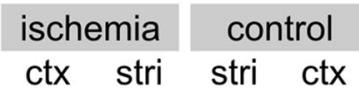

NF-L $\quad \begin{array}{r}100 \mathrm{kDa}- \\ 75 \mathrm{kDa}-\end{array}$

stri stri ctx

(pab)

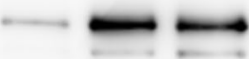

$50 \mathrm{kDa}$ -

$37 \mathrm{kDa}$ -

ß-actin 50kDa-

$37 \mathrm{kDa}-$

pronounced after $24 \mathrm{~h}-\mathrm{p}$, but failed to reach statistical significance. NF-L levels after $4 \mathrm{~h}-\mathrm{t}$ remained mostly unaltered. e, f NF-L degradation products of 40-65 kDa are significantly increased after $24 \mathrm{~h}-\mathrm{p} . n=5-6$. Data are presented as mean values; error bars indicate the standard error. $* * p<0.01, * * * p<0.001$

significant reduction of MAP2 and NF-L serum levels over time was observed in patients with lacunar stroke (Fig. 7b).

Similar to the described results, the comparison between TIA patients and a combined group including patients with 


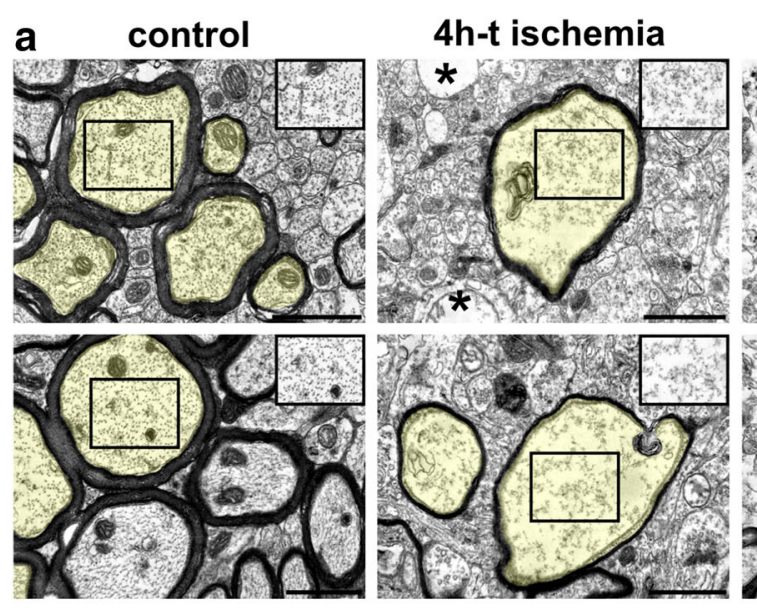

Fig. 5 a Electron microscopy images show cross sections of cortical axons after $4 \mathrm{~h}$ and $24 \mathrm{~h}$ of transient ischemia in mice and unaffected contralateral regions. For illustration, transversally sectioned axons are transparently highlighted in yellow. The regular distribution of axonal neurofilaments is lost (insets) $4 \mathrm{~h}$ and $24 \mathrm{~h}$ after tMCAO. An ischemiainduced cellular edema is indicated by a less electron dense cytoplasm in the highlighted axons and insets as well as in non-axonal structures 24h-t ischemia

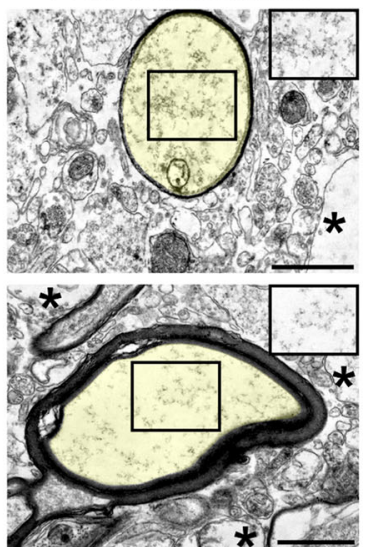

b

neurofilament density

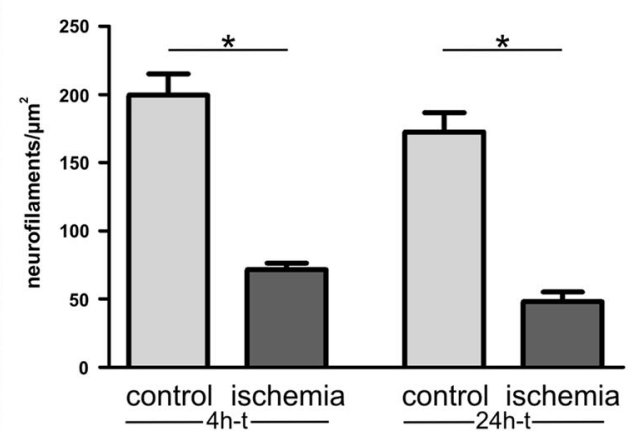

(asterisks). Please note that the images and insets also contain other components of the axonal cytoplasm which were not considered for the analysis of neurofilament density. b The density of detectable neurofilaments is decreased in ischemia-affected cortical axons $4 \mathrm{~h}$ and $24 \mathrm{~h}$ after tMCAO. $n=5$. Data are presented as mean values; error bars indicate the standard error. ${ }^{*} p<0.05$. Scale bars: $1 \mu \mathrm{m}$

and without intervention (Suppl. Figure 3) also exhibited significantly different levels of MAP2 between TIA and stroke patients at day $1(p=0.0012)$ and day $3(p=0.0079)$ with higher values in stroke patients, while serum levels of NF-L failed to provide a significant difference (day $1 p=0.5531$; day $3 p=0.4457$ ).

As significant elevations of blood serum levels are not observed for NF-L, MAP2 is likely to represent a more sensitive biomarker for ischemia-induced tissue damage. However, neither NF-L nor MAP2 serum levels showed a significant correlation to the severity of the neurological deficit as assessed by the NIHSS (not shown).

\section{Discussion}

This study explores alterations of the cytoskeletal elements NF-L and MAP2 in the setting of stroke in order to evaluate their potential use for neuroprotective approaches and biomarker analyses. Considering evident translational hurdles from bench to bedside [57-59], this study for the first time addresses cytoskeletal elements in a combined preclinical and clinical setup with comparable timelines and interventions regarding recanalizing techniques. To allow a spatio-temporal characterization of cytoskeletal alterations, animal experiments were furthermore performed with different observation periods after ischemia induction.

In general, neurofilaments and MAP2 have been recognized as elements of the neuronal cytoskeleton, which are exceptionally prone to ischemia-mediated damage [18-20, 22, 23, 40]. Therefore, both proteins have turned into focus in stroke research as alterations of the neuronal cytoskeleton have been considered to mediate the transition of a reversible to an irreversible neuronal damage and to maintain cellular integrity [12, 13, 25]. Moreover, their clinical use as biomarkers correlating with the severity of neural tissue damage has been repeatedly suggested $[28,31,35$, $43,60,61]$. Especially the neurofilament subunit NF-L is increasingly acknowledged as biomarker in neurological disorders. Upon axonal damage and neuronal damage or death, NF-L is first released into the interstitial fluids and then to the cerebrospinal fluid and to the blood where its increased levels can be detected $[26,27,32,62,63]$. On the other hand, despite its acute sensitivity to ischemic insults $[36,40,64]$ and its ischemiaassociated degradation by the $\mathrm{Ca}^{2+}$-dependent proteases calpain and caspase [38,39], the value of MAP2 as a potential biomarker in the clinical setting of stroke has so far been largely neglected.

\section{Alterations of MAP2 and NF-L in the Applied Animal Models of Cerebral Ischemia}

In line with reports describing early ischemia-associated loss of MAP2 [39, 40, 65], the here presented immunofluorescence and Western blot analyses in mice and rats revealed that an ischemia-associated reduction of MAP2 occurs early (4h after MCAO) and uniformly throughout the infarct area (Figs. 1, 2, and 3, Suppl. Figure 2). An exception represented the model of $4 \mathrm{~h}$ transient MCAO, where the demarcation of the infarct border was not yet pronounced (Fig. 1). Interestingly, both Western blot and immunofluorescence analyses revealed an abrupt, but constant reduction of MAP2 levels in 4h-p tissue, which did not further decrease over time. This observation may be explained by the fact that the expansion of the infarct already reaches its maximum within $3 \mathrm{~h}$ in the model of 

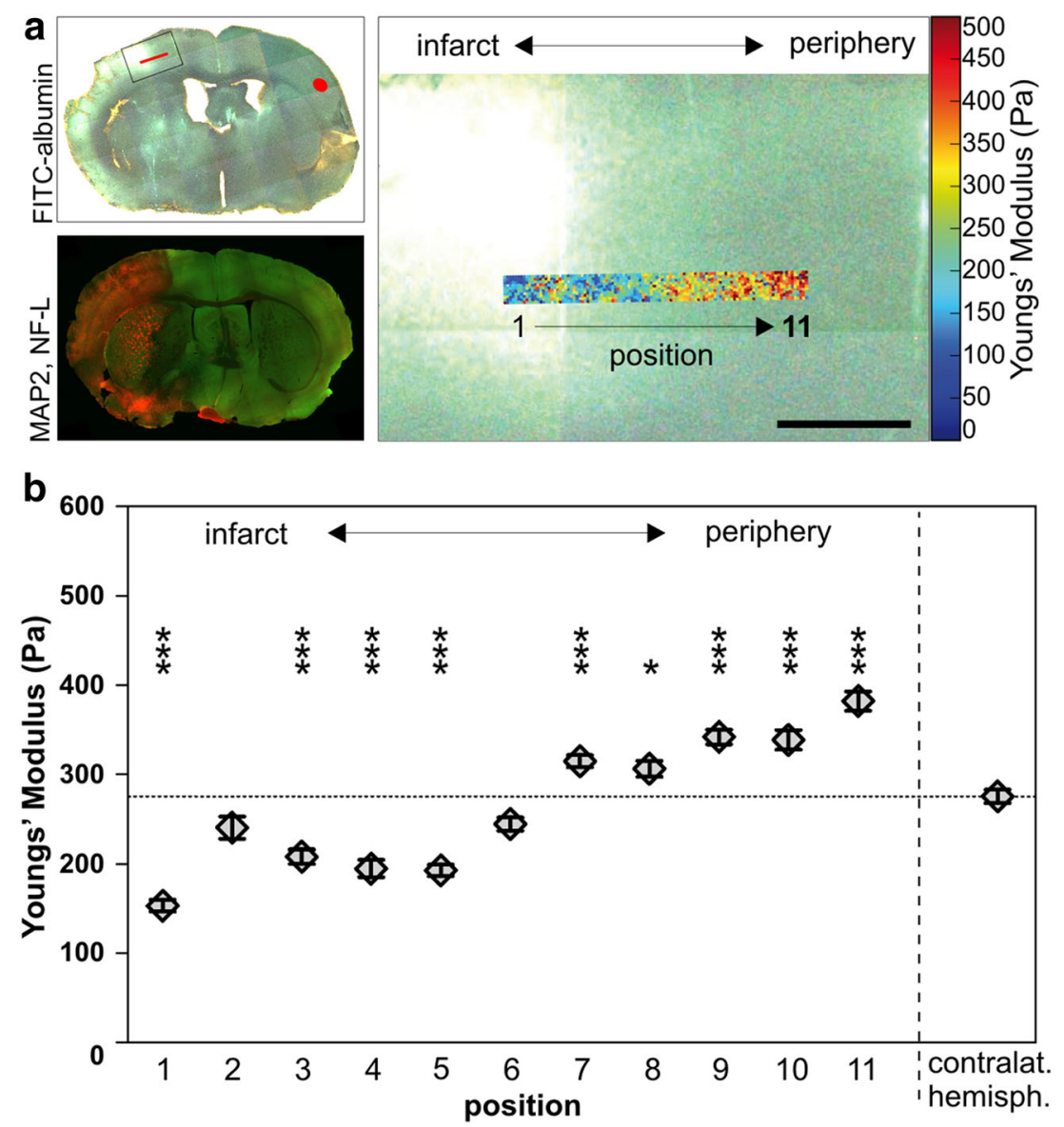

Fig. 6 The elastic modulus of infarcted brain tissue, an indicator of tissue elasticity, was measured in a cortex of a $24 \mathrm{~h}-\mathrm{p}$ mouse by AFM indentation. a Upper left image: Overview of the measured brain slice illustrates the localization of the measurements. The ischemia-affected tissue was identified by areas of FITC-albumin extravasation (green/ white). To enhance the visibility of the contralateral hemisphere on behalf of figure generation, the image was acquired with fluorescence and transmitted light. Lower left image: Overview of MAP2- (green) and NF-L (red)-labeled coronal brain slice captured with epifluorescence microscopy to illustrate that the AFM measurements

permanent $\mathrm{MCAO}$ and further highlights the rapid and prolonged loss of MAP2 due to ischemia [66].

Contrary to the reduced immunofluorescence intensity of MAP2 in infarcted regions, the NF-L-related immunofluorescence intensity is apparently increased in ischemia-affected areas. This contradictory finding may be explained by the calpain- and caspase-dependent degradation of neurofilaments $[13,38,39]$. In line with previous reports $[20,67,68]$, the therefore increased availability of smaller protein fragments of lower molecular weight can also be detected by available polyclonal antibodies used for immunofluorescence labeling (Fig. 4e and f). Consequentially, the increased immunoreactivity of NF-L in ischemia-affected areas has to be interpreted with caution, as it does not reflect an overall increase of NF$\mathrm{L}$ protein levels but likely originates from the abundance of NF-L protein fragments [20]. comply with the infarct border visualized by immunofluorescence labeling. Right image: Higher magnification of the inset (upper left image) showing an overlay of the infarct border and the heat map (blue corresponds to softer and red to stiffer regions) of the AFM measurements. b Over a span of $1100 \mu \mathrm{m}$ (positions 1-11), measurements revealed decreased values of tissue elasticity in central regions $(1,3,4,5)$, whereas peripheral regions $(7,8,9,10,11)$ exhibited an elevated elastic modulus. Each region includes 100 individual measurements. Data are presented as mean values; error bars indicate the standard error. Scale bar: $500 \mu \mathrm{m}$

\section{MAP2 as a Biomarker for Early Neuronal Damage After Stroke}

Even though MAP2 serum levels were shown to increase in an animal model of experimental cerebral ischemia [43] and in patients suffering from TBI [61], clinical data of stroke patients are still lacking. The possible use of MAP2 as a stroke biomarker was therefore addressed in comparison to NF-L, which is already conceived as a valuable biomarker for acute neuronal damage [26, 27, 31].

Our preclinical data suggests a high sensitivity of MAP2 to ischemia, which is also reflected by our analyses of human blood samples, as patients suffering from stroke exhibited significantly higher MAP2 serum levels than patients suffering from TIA (Fig. 6a). Furthermore, the MAP2 serum analyses indicate a correlation with the size of the ischemic lesion, 
Table 2 Patients' characteristics

Overall sample $(n=81)$

TIA $(n=17)$

Stroke $(n=37)$

Stroke with

intervention $(n=27)$

\section{Basic data}

Age $(\mathrm{M} \pm \mathrm{SD})$

Gender (female $n(\%)$ )

Clinical data

NIHSS $(\mathrm{M} \pm \mathrm{SD})$ at admission

Infarct size

Lacunar, diameter $\leq 1.5 \mathrm{~cm}(n(\%))$

Large, diameter $>1.5 \mathrm{~cm}(n(\%))$

None $(n(\%))$

Infarct location

Middle cerebral artery $(n(\%))$

Anterior cerebral artery $(n(\%))$

Posterior cerebral artery $(n(\%))$

Vertebrobasilar territory $(n(\%))$

Multiple locations $(n(\%))$

None $(n(\%))$

Infarct etiology

Large artery atherosclerosis $(n(\%))$

Artery to artery embolism $\$(n(\%))$

Cardioembolism $^{\S}(n(\%))$

Small vessel occlusion $(n(\%))$

Others $(n(\%))$

Unknown (n (\%))

Medical history

Arterial hypertension $(n(\%))$

Diabetes mellitus $(n(\%))$

Nicotine $^{\#}(n(\%))$

Hyperlipidemia $(n(\%))$

Atrial fibrillation $(n(\%))$

Treatment

Intravenous thrombolysis $(n(\%))$

Endovascular treatment $(n(\%))$

Combined approach $(n(\%))$

Time point of blood collection

Onset to 1 collection (days $\mathrm{M} \pm \mathrm{SD}$ )

Onset to 2 collection (days $\mathrm{M} \pm \mathrm{SD}$ )

$66.5 \pm 13.9$
$31(38.3)$
$4.4 \pm 6.1$
$24(29.6)$
$40(49.4)$
$17(21.0)$
$35(43.2)$
$2(2.5)$
$8(9.9)$
$10(12.3)$
$9(11.1)$
$17(21.0)$
$18(22.2)$
$31(38.3)$
$15(18.5)$
$4(4.9)$
$5(6.2)$
$8(9.9)$

67 (82.7)

$32(39.5)$

39 (48.1)

$50(61.7)$

$11(13.6)$
$66.4 \pm 15.8$

$10(58.8)$

$0.5 \pm 0.8$

$-$

-

$17(100)$$$
\text { - }
$$$$
17(100)
$$

1 (5.9)

7 (41.1)

2 (11.8)

1 (5.9)

$2(11.8)$

4 (23.5)

12 (70.6)

4 (23.5)

7 (41.2)

9 (52.9)

1 (5.9)

$1.1(0.6)$

$3.5(0.8)$

$1.1(0.7)$

$3.4(0.7)$
$69.0 \pm 13.0$

15 (40.5)

$63.2 \pm 13.6$

6 (22.2)

$9.9 \pm 7.7$

7 (25.9)

$20(74.1)$

20 (54.1)

18 (48.7)

$17(63.0)$

$2(5.4)$

7 (18.9)

1 (3.7)

$6(16.2)$

$4(14.8)$

5 (18.5)

$4(10.8)$

$7(26.0)$

8 (29.6)

$8(29.6)$

$5(13.5)$

-

$3(8.1)$

$2(7.4)$

$1(2.7)$

2 (7.4)

2 (5.4)

21 (77.8)

7 (25.9)

13 (48.1)

19 (70.4)

$7(25.9)$

$14(51.9)$

7 (25.9)

$6(22.2)$

$1.3(0.7)$

$0.9(0.3)$

$3.7(0.9)$

$3.2(0.8)$

\# Including current and previous nicotine consumption

\$Including relevant carotid macroangiopathy and carotid plaque load based on ultrasound evaluation without consecutive stenosis of less than $50 \%$ but with suspected artery to artery embolism

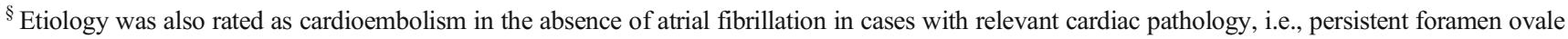

showing significantly higher values in patients with larger ischemic lesions compared to patients with small ischemic lesions.

Of note, these clinical observations are supported by our preclinical immunofluorescence experiments, showing a uniform reduction of MAP2 is throughout the lesion, whereas
NF-L exhibits regional differences. As MAP2 was further shown to be reduced earlier due to ischemia than NF-L (Figs. 1, 2, 4), these regional differences may reflect the heterogeneous distribution of NF-L [69] or also regional differences of the ischemic affection within the ischemic lesion [70, 71]. Therefore, compared to MAP2, serum levels of NF-L are 

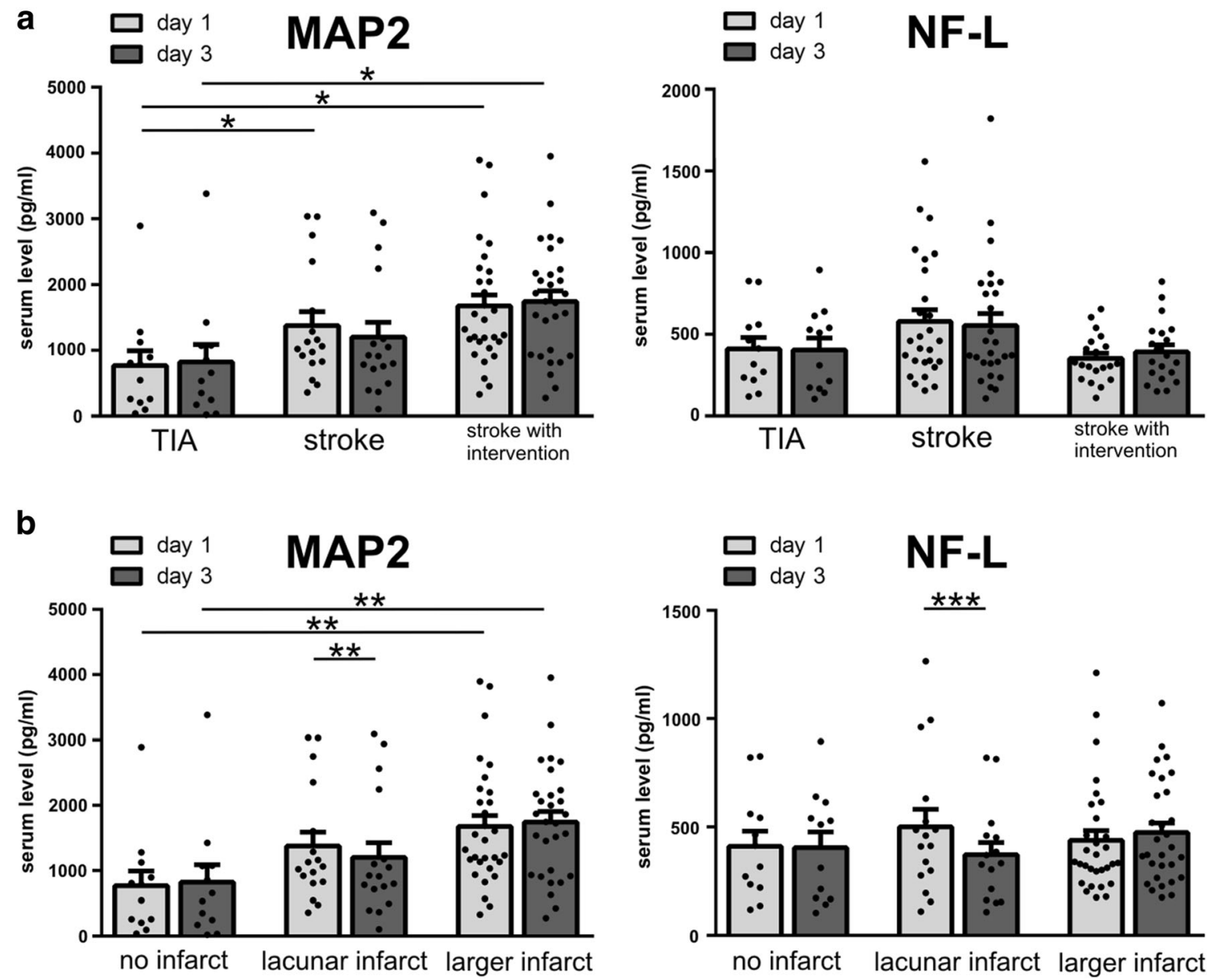

Fig. 7 MAP2 and NF-L serum levels of patients suffering from stroke at day 1 and day 3 after stroke onset: patients were divided into groups depending on a stroke intervention or $\mathbf{b}$ the size of the ischemic lesion. Patients with stroke (with and without intervention) have significantly higher serum concentrations of MAP2 than patients suffering from TIA. Significantly higher MAP2 serum levels are also found in patients

likely to have higher fluctuations between individuals in dependence of the ischemic region and thus a lower correlation with the infarct size. Although NF-L levels were shown to correlate with the infarct volume or the severity of clinical symptoms as assessed by the NIHSS [28, 29, 32-34], methodological or regional differences may explain why these correlations could not be confirmed in this study.

There has further been evidence that an acute loss of MAP2 may not necessarily imply neuronal death but that a MAP2 recovery might be possible after an injury of moderate severity such as after moderate TBI [65]. This is of special interest, as MAP2 blood levels in rats subjected to MCAO were shown to peak even before the appearance of ischemic lesions could be visualized by triphenyl tetrazolium chloride (TTC) staining [43]. Since the lesion volume identified by TTC staining correlates with volume of the lesion as identified by magnetic resonance or computed tomography imaging [72-75], MAP2 blood measurements might potentially capture early suffering from larger infarcts compared to no ischemic lesion. Significant differences between day 1 and day 3 are only found after a lacunar stroke (MAP2 and NF-L). $\mathbf{a}$ and $\mathbf{b}: n=12-30$. Bars represent mean values; dots represent individual values; error bars indicate the standard error. $* p<0.05, * * p<0.01, * * * p<0.001$

neuronal damage that is not yet detectable with standard neuroimaging techniques.

Taking these aspects into consideration and given that the serum levels of MAP2 exhibited a more pronounced increase compared to NF-L, MAP2 is likely to represent a more sensitive biomarker for early ischemia-induced neuronal damage.

\section{Reperfusion Versus Permanent Occlusion}

With reference to a postulated reperfusion injury [76], the present study also included models of permanent and transient ischemia in mice and rats at different time points. Here, immunofluorescence and Western blot analyses of MAP2 and full-protein NF-L did not reveal significant differences between transient and permanent models (Figs. 1, 2, 3, and 4). Thus, neither the dreaded reperfusion injury [76] nor any benefits of reperfusion [77] could be captured by analyzing MAP2 or NF-L in the applied animal models. 
Of note, although the analysis of human serum levels only exhibited a numerical trend toward decreased NF-L serum concentrations in stroke patients who underwent recanalizing therapies, the resulting values after acute therapy are comparable with TIA patients and therefore comply with studies suggesting serum NF-L measurements as a useful tool to monitor treatment responses in neurological diseases [78, 79].

Interestingly, the level of MAP2 serum concentrations appeared to be higher in stroke patients with therapies aiming on vessel recanalization than in stroke patients without such treatments. This observation is in excellent accordance with previous experiments in rats, where the amount of MAP2 released into the blood was markedly increased by reperfusion [43]. A long-lasting release of MAP2 into the blood is also described in survivors of severe TBI, where MAP2 levels were significantly higher in patients with high cognitive function compared to patients in a vegetative state [61]. Considering the dynamic functions of MAP2 in the growth, differentiation, and plasticity of neurons, especially in dendrites [80], the presented results suggest that elevated MAP2 serum levels might serve as a biomarker not only for acute neuronal damage but also for neuronal regeneration after stroke. Since remodeling and restored dendrite function can be observed in peri-infarct neurons after stroke [81], MAP2 serum level alterations might well represent the fraction of moderately, potentially reversibly damaged neurons of the penumbra.

\section{Ultrastructural Alterations and Impaired Tissue Integrity}

To investigate whether the described ischemia-induced alterations of the neuronal cytoskeleton can also be captured at an ultrastructural level, electron microscopy was applied to analyze the neurofilament density of cortical axons (Fig. 5). The here observed decrease of neurofilament density appears in line with the above-described reduction of NF-L protein as well as of other neurofilament proteins due to ischemia [20]. Of course, the here captured neurofilaments only represent the proportion of neurofilaments, which remained detectable by electron microscopy in the analyzed ischemia-affected axons, while degradation products or smaller protein fragments may not remain distinguishable from other ischemia-affected components of the axonal cytoplasm. These degraded protein fragments $[67,68]$, which are likely responsible for the observed increase of NF-L-related immunofluorescence intensity, cannot be recognized with this method. Therefore, the reduced density of detectable neurofilaments cannot represent a direct measure of the protein concentration. Nevertheless, the described ultrastructural alterations can be correlated with the observed reduction of NF-L and MAP2 protein levels (Fig. 4) as well as their altered patterns of immunofluorescence intensity.
Further, the confirmation of a cellular edema in the analyzed regions is in line with the reported cytotoxic edema of cells in the ischemia-affected areas including the ischemic penumbra $[82,83]$ and thereby also correlates with an impaired but potentially restorable neuronal function [70, 84]. However, in the analyzed axons, the reduced electron density of the axonal cytoplasm is likely to represent both an increased water content due to a cellular edema and an impaired cytoskeletal network, as shown by the reduced neurofilament density.

As an impaired function of the neuronal cytoskeleton also impacts on cellular integrity [13], we further explored mechanical properties of the ischemia-affected tissue with atomic force microscopy. Importantly, the elastic strength was found to be decreased in central regions of the ischemic tissue, whereas increased values were found in peripheral regions (Fig. 6). These supposedly contradictory findings illustrate the naturally expected variations of ischemia-induced tissue affection with different degrees of tissue damage according to the penumbra concept $[70,82,84]$. The varying mechanical properties are likely to be explained by more pronounced tissue damage in the center of the ischemic lesion, where irreversible tissue damage leads to loss of cellular integrity and thus decreased values of the elastic strength. Since MAP2 is an important regulator of the neuronal cytoskeleton which stabilizes microtubules, bundles actin filaments, and crosslinks the cellular cytoskeleton $[85,86]$, the reduction of MAP2 levels in the ischemic region is likely to explain the described softening of the tissue as a consequence of an impaired cytoskeleton.

Further, intermediate filaments such as neurofilaments are known to enable cells to withstand severe deformations [87]. Vice versa, the ultrastructural confirmation of decreased neurofilament densities could also be linked to the decreased tissue stiffness.

In contrast, in peripheral areas of the ischemic penumbra, the intracellular edema in combination with preserved cellular integrity could be responsible for the increased elastic strength in these regions.

Other possible reasons for the observed stiffening could relate to increased actin (stress) fiber generation as reaction to oxygen depletion $[88,89]$ or to reactions caused by changes of local $\mathrm{pH}[90]$ in areas of potentially reversible tissue damage. Although AFM measurements can be influenced by various variables, the presented values of the elastic strength appear to be plausible since comparable values were observed when analyzing living neurons under cell culture conditions [91]. Since AFM measurements could not directly be performed on the MAP2-/NF-L-immunolabeled sections for technical reasons, identification of the infarcted tissue was ensured by detection of areas showing FITC-albumin extravasation. Similar to areas of increased NF-L immunoreactivity, FITC-albumin extravasation was shown to include regions of 
the ischemic penumbra $[20,54]$ and therefore areas of potentially salvageable tissue [70].

\section{Summary and Conclusion}

In a translational approach with different animal models as well as human serum samples, the present study reveals an early and uniform reduction of MAP2 throughout the ischemic lesion. Furthermore, a regionally dependent increase of NF-L-related immunofluorescence intensity is demonstrated in the ischemic tissue, which most likely originates from the binding of NF-L degradation products. The ischemia-induced reduction of MAP2 and NF-L full-length protein is further confirmed at the protein level, at the ultrastructural level, and by a decreased elastic strength of the ischemia-affected tissue. Since the described alterations are shown to include areas of the penumbra $[20,54]$, NF-L and MAP2 might represent promising targets for upcoming neuroprotective therapies. Importantly, a direct comparison of NF-L and MAP2 in human blood samples highlights MAP2 as the more sensitive biomarker in stroke patients.

Supplementary Information The online version contains supplementary material available at https://doi.org/10.1007/s12035-021-02372-3.

Acknowledgements The authors thank Daniela Urban, Rita Lachmund, and Dr. Johann Pelz (Leipzig University, Leipzig, Germany) for the assistance concerning patient recruitment and blood sampling in the clinical study.

Author Contribution Study design: DM, MK, and BM. Manuscript preparation: $\mathrm{BM}, \mathrm{MK}$, and $\mathrm{DM}$. Statistical analysis and figure generation: BM. Animal experiments and associated regulatory affairs: DM, MK, and BM. Regulatory affairs for the clinical study: DM. Immunofluorescence labeling and microscopy: BM. Western Blot analysis: $\mathrm{CH}$ and BM. Electron microscopy: MK. Atomic force microscopy: TF and AB. ELISA measurements: $\mathrm{AB}$ and SA. Assistance in human cerebral imaging: SS. Overall project acquisition and preliminary work: DM with assistance from $\mathrm{WH}$ and $\mathrm{MK}$.

Funding Open Access funding enabled and organized by Projekt DEAL. Parts of this study were supported by the Europäischer Sozialfonds [ESF, grant 100270131 to DM]. TF was funded by ERC Advanced Grant 741350 .

Availability of Data and Materials The datasets analyzed during the current study are available from the corresponding author on reasonable request.

Code Availability Matlab code used in AFM data processing is available from $\mathrm{TF}$ upon reasonable request.

\section{Declarations}

Ethics Approval Animal experiments were performed according to the European Union Directive 2010/63/EU and the German guideline for care and use of laboratory animals, and reporting followed the ARRIVE guidelines [92]. All procedures were approved by local authorities (Regierungspräsidium Leipzig; reference number TVV 02/17).

Human blood sampling was performed from 2018 to 2019, after positive evaluation from the local ethics committee (Ethical Committee at the Medical Faculty; Leipzig University, reference number 226/18-ek).

Consent to Participate Not applicable.

Consent for Publication Not applicable.

Competing Interests The authors declare they have no competing interests.

Open Access This article is licensed under a Creative Commons Attribution 4.0 International License, which permits use, sharing, adaptation, distribution and reproduction in any medium or format, as long as you give appropriate credit to the original author(s) and the source, provide a link to the Creative Commons licence, and indicate if changes were made. The images or other third party material in this article are included in the article's Creative Commons licence, unless indicated otherwise in a credit line to the material. If material is not included in the article's Creative Commons licence and your intended use is not permitted by statutory regulation or exceeds the permitted use, you will need to obtain permission directly from the copyright holder. To view a copy of this licence, visit http://creativecommons.org/licenses/by/4.0/.

\section{References}

1. Friede RL, Samorajski T (1970) Axon caliber related to neurofilaments and microtubules in sciatic nerve fibers of rats and mice. Anat Rec 167:379-387. https://doi.org/10.1002/ar. 1091670402

2. Hoffman PN, Griffin JW, Price DL (1984) Control of axonal caliber by neurofilament transport. J Cell Biol 99:705-714. https://doi.org/ 10.1083/jcb.99.2.705

3. Hoffman PN, Cleveland DW, Griffin JW, Landes PW, Cowan NJ, Price DL (1987) Neurofilament gene expression: a major determinant of axonal caliber. Proc Natl Acad Sci U S A 84:3472-3476. https://doi.org/10.1073/pnas.84.10.3472

4. Križ J, Zhu Q, Julien J-P, Padjen AL (2000) Electrophysiological properties of axons in mice lacking neurofilament subunit genes: disparity between conduction velocity and axon diameter in absence of NF-H. Brain Res 885:32-44. https://doi.org/10.1016/ s0006-8993(00)02899-7

5. Griffin JW, Watson DF (1988) Axonal transport in neurological disease. Ann Neurol 23:3-13. https://doi.org/10.1002/ana. 410230103

6. Guillaud L, El-Agamy SE, Otsuki M et al (2020) Anterograde axonal transport in neuronal homeostasis and disease. Front Mol Neurosci 13:556175. https://doi.org/10.3389/fnmol.2020.556175

7. Yates DM, Manser C, de Vos KJ, Shaw CE, McLoughlin DM, Miller CCJ (2009) Neurofilament subunit (NFL) head domain phosphorylation regulates axonal transport of neurofilaments. Eur J Cell Biol 88:193-202. https://doi.org/10.1016/j.ejcb.2008.11.004

8. Yuan A, Sershen H, Veeranna et al (2015) Neurofilament subunits are integral components of synapses and modulate neurotransmission and behavior in vivo. Mol Psychiatry 20:986-994. https://doi. org/10.1038/mp.2015.45

9. Gambino G, Rizzo V, Giglia G, Ferraro G., Sardo P. (2020) Microtubule dynamics and neuronal excitability: advances on cytoskeletal components implicated in epileptic phenomena. Cell Mol Neurobiol. https://doi.org/10.1007/s10571-020-00963-7 
10. Sferra A, Nicita F, Bertini E (2020) Microtubule dysfunction: a common feature of neurodegenerative diseases. Int J Mol Sci 21. https://doi.org/10.3390/ijms21197354

11. Zucchi E, Bonetto V, Sorarù G, Martinelli I, Parchi P, Liguori R, Mandrioli J (2020) Neurofilaments in motor neuron disorders: towards promising diagnostic and prognostic biomarkers. Mol Neurodegener 15:58. https://doi.org/10.1186/s13024-020-00406-3

12. Dewar D, Dawson DA (1997) Changes of cytoskeletal protein immunostaining in myelinated fibre tracts after focal cerebral ischaemia in the rat. Acta Neuropathol 93:71-77. https://doi.org/10.1007/ s004010050584

13. Ogata N, Yonekawa Y, Taki W, Kannagi R, Murachi T, Hamakubo T, Kikuchi H (1989) Degradation of neurofilament protein in cerebral ischemia. J Neurosurg 70:103-107. https://doi.org/10.3171/ jns.1989.70.1.0103

14. Campbell BCV, de Silva DA, Macleod MR, Coutts SB, Schwamm LH, Davis SM, Donnan GA (2019) Ischaemic stroke. Nat Rev Dis Primers 5:70. https://doi.org/10.1038/s41572-019-0118-8

15. Virani SS, Alonso A, Benjamin EJ, Bittencourt MS, Callaway CW, Carson AP, Chamberlain AM, Chang AR et al (2020) Heart disease and stroke statistics-2020 update: a report from the American Heart Association. Circulation 141:e139-e596. https://doi.org/10.1161/ CIR.0000000000000757

16. Goyal M, Menon BK, van Zwam WH, Dippel DWJ, Mitchell PJ, Demchuk AM, Dávalos A, Majoie CBLM et al (2016) Endovascular thrombectomy after large-vessel ischaemic stroke: a meta-analysis of individual patient data from five randomised trials. Lancet 387:1723-1731. https://doi.org/10.1016/S0140-6736(16) 00163-X

17. Hacke W, Kaste M, Bluhmki E, Brozman M, Dávalos A, Guidetti D, Larrue V, Lees KR et al (2008) Thrombolysis with alteplase 3 to 4.5 hours after acute ischemic stroke. N Engl J Med 359:13171329. https://doi.org/10.1056/NEJMoa0804656

18. Hayes RL, Yang K, Whitson JS et al (1995) Cytoskeletal derangements following central nervous system injury: modulation by neurotrophic gene transfection. J Neurotrauma 12:933-941. https://doi. org/10.1089/neu.1995.12.933

19. Leifer D, Kowall NW (1993) Immunohistochemical patterns of selective cellular vulnerability in human cerebral ischemia. $\mathrm{J}$ Neurol Sci 119:217-228

20. Mages B, Aleithe S, Altmann S, Blietz A, Nitzsche B, Barthel H, Horn AKE, Hobusch C et al (2018) Impaired neurofilament integrity and neuronal morphology in different models of focal cerebral ischemia and human stroke tissue. Front Cell Neurosci 12:161. https://doi.org/10.3389/fncel.2018.00161

21. Michalski D, Preißler H, Hofmann S, Kacza J, Härtig W (2016) Decline of microtubule-associated protein tau after experimental stroke in differently aged wild-type and $3 \times \mathrm{Tg}$ mice with Alzheimer-like alterations. Neuroscience 330:1-11. https://doi. org/10.1016/j.neuroscience.2016.05.013

22. Posmantur RM, Kampfl A, Liu SJ, Heck K, Taft WC, Clifton GL, Hayes RL (1996) Cytoskeletal derangements of cortical neuronal processes three hours after traumatic brain injury in rats: an immunofluorescence study. J Neuropathol Exp Neurol 55:68-80

23. Schroeder E, Vogelgesang S, Popa-Wagner A, Kessler C (2003) Neurofilament expression in the rat brain after cerebral infarction: effect of age. Neurobiol Aging 24:135-145. https://doi.org/10. 1016/S0197-4580(02)00063-5

24. Lobsiger CS, Cleveland DW (2009) Neurofilaments: organization and function in neurons. Encyclopedia of Neuroscience. Elsevier, In, pp. 433-436

25. Yuan A, Rao MV, Veeranna et al (2012) Neurofilaments at a glance. J Cell Sci 125:3257-3263. https://doi.org/10.1242/jcs. 104729

26. O'Connell GC, Alder ML, Smothers CG et al (1739) Diagnosis of ischemic stroke using circulating levels of brain-specific proteins measured via high-sensitivity digital ELISA. Brain Res 2020: 146861. https://doi.org/10.1016/j.brainres.2020.146861

27. Gendron TF, Badi MK, Heckman MG, Jansen-West KR, Vilanilam GK, Johnson PW, Burch AR, Walton RL et al (2020) Plasma neurofilament light predicts mortality in patients with stroke. Sci Transl Med 12:eaay1913. https://doi.org/10.1126/scitranslmed.aay1913

28. Tiedt S, Duering M, Barro C, Kaya AG, Boeck J, Bode FJ, Klein M, Dorn F et al (2018) Serum neurofilament light: a biomarker of neuroaxonal injury after ischemic stroke. Neurology 91:e1338e1347. https://doi.org/10.1212/WNL.0000000000006282

29. Onatsu J, Vanninen R, Jäkälä P, Mustonen P, Pulkki K, Korhonen M, Hedman M, Zetterberg H et al (2019) Serum neurofilament light chain concentration correlates with infarct volume but not prognosis in acute ischemic stroke. J Stroke Cerebrovasc Dis 28:22422249. https://doi.org/10.1016/j.jstrokecerebrovasdis.2019.05.008

30. Khalil M, Teunissen CE, Otto M, Piehl F, Sormani MP, Gattringer T, Barro C, Kappos L et al (2018) Neurofilaments as biomarkers in neurological disorders. Nat Rev Neurol 14:577-589. https://doi. org/10.1038/s41582-018-0058-Z

31. Uphaus T, Bittner S, Gröschel S, Steffen F, Muthuraman M, Wasser K, Weber-Krüger M, Zipp F et al (2019) NfL (neurofilament light chain) levels as a predictive marker for long-term outcome after ischemic stroke. Stroke 50:3077-3084. https://doi.org/ 10.1161/STROKEAHA.119.026410

32. de Marchis GM, Katan M, Barro C, Fladt J, Traenka C, Seiffge DJ, Hert L, Gensicke H et al (2018) Serum neurofilament light chain in patients with acute cerebrovascular events. Eur J Neurol 25:562568. https://doi.org/10.1111/ene.13554

33. Traenka C, Disanto G, Seiffge DJ, Gensicke H, Hert L, GrondGinsbach C, Peters N, Regeniter A et al (2015) Serum neurofilament light chain levels are associated with clinical characteristics and outcome in patients with cervical artery dissection. Cerebrovasc Dis 40:222-227. https://doi.org/10.1159/000440774

34. Pedersen A, Stanne TM, Nilsson S, Klasson S, Rosengren L, Holmegaard L, Jood K, Blennow K et al (2019) Circulating neurofilament light in ischemic stroke: temporal profile and outcome prediction. J Neurol 266:2796-2806. https://doi.org/10.1007/ s00415-019-09477-9

35. Nielsen HH, Soares CB, Høgedal SS, Madsen JS, Hansen RB, Christensen AA, Madsen C, Clausen BH et al (2020) Acute neurofilament light chain plasma levels correlate with stroke severity and clinical outcome in ischemic stroke patients. Front Neurol 11:1317. https://doi.org/10.3389/fneur.2020.00448

36. Inuzuka T, Tamura A, Sato S, Kirino T, Yanagisawa K, Toyoshima I, Miyatake T (1990) Changes in the concentrations of cerebral proteins following occlusion of the middle cerebral artery in rats. Stroke 21:917-922. https://doi.org/10.1161/01.STR.21.6.917

37. Hirokawa N (1994) Microtubule organization and dynamics dependent on microtubule-associated proteins. Curr Opin Cell Biol 6:74 81. https://doi.org/10.1016/0955-0674(94)90119-8

38. Rami A, Krieglstein J (1993) Protective effects of calpain inhibitors against neuronal damage caused by cytotoxic hypoxia in vitro and ischemia in vivo. Brain Res 609:67-70. https://doi.org/10.1016/ 0006-8993(93)90856-I

39. Yanagihara T, Brengman JM, Mushynski WE (1990) Differential vulnerability of microtubule components in cerebral ischemia. Acta Neuropathol 80:499-505. https://doi.org/10.1007/BF00294610

40. Dawson DA, Hallenbeck JM (1996) Acute focal ischemia-induced alterations in MAP2 immunostaining: description of temporal changes and utilization as a marker for volumetric assessment of acute brain injury. J Cereb Blood Flow Metab 16:170-174. https:// doi.org/10.1097/00004647-199601000-00020

41. Härtig W, Krueger M, Hofmann S, Preißler H, Märkel M, Frydrychowicz C, Mueller WC, Bechmann I et al (2016) Upregulation of neurofilament light chains is associated with diminished immunoreactivities for MAP2 and tau after ischemic stroke in 
rodents and in a human case. J Chem Neuroanat 78:140-148. https://doi.org/10.1016/j.jchemneu.2016.09.004

42. Michalski D, Härtig W, Krügel K, Edwards RH, Böddener M, Böhme L, Pannicke T, Reichenbach A et al (2013) Regionspecific expression of vesicular glutamate and GABA transporters under various ischaemic conditions in mouse forebrain and retina. Neuroscience 231:328-344. https://doi.org/10.1016/j. neuroscience.2012.11.046

43. Park D, Joo SS, Lee HJ, Choi KC, Kim SU, Kim YB (2012) Microtubule-associated protein 2, an early blood marker of ischemic brain injury. J Neurosci Res 90:461-467. https://doi.org/10. 1002/jnr.22769

44. Menzies SA, Hoff JT, Betz AL (1992) Middle cerebral artery occlusion in rats: a neurological and pathological evaluation of a reproducible model. Neurosurgery:100-106

45. Longa EZ, Weinstein PR, Carlson S, Cummins R (1989) Reversible middle cerebral artery occlusion without craniectomy in rats. Stroke 20:84-91. https://doi.org/10.1161/01.STR.20.1.84

46. Hawkes CA, Michalski D, Anders R, Nissel S, Grosche J, Bechmann I, Carare RO, Härtig W (2013) Stroke-induced opposite and age-dependent changes of vessel-associated markers in comorbid transgenic mice with Alzheimer-like alterations. Exp Neurol 250:270-281. https://doi.org/10.1016/j.expneurol.2013.09. 020

47. Zhang RL, Chopp M, Zhang ZG, Jiang Q, Ewing JR (1997) A rat model of focal embolic cerebral ischemia. Brain Res 766:83-92

48. Michalski D, Küppers-Tiedt L, Weise C, Laignel F, Härtig W, Raviolo M, Schneider D, Hobohm C (2009) Long-term functional and neurological outcome after simultaneous treatment with tissueplasminogen activator and hyperbaric oxygen in early phase of embolic stroke in rats. Brain Res 1303:161-168. https://doi.org/ 10.1016/j.brainres.2009.09.038

49. Hata R, Mies G, Wiessner C, Fritze K, Hesselbarth D, Brinker G, Hossmann KA (1998) A reproducible model of middle cerebral artery occlusion in mice: hemodynamic, biochemical, and magnetic resonance imaging. J Cereb Blood Flow Metab 18:367-375. https:// doi.org/10.1097/00004647-199804000-00004

50. Krueger M, Härtig W, Reichenbach A, Bechmann I, Michalski D (2013) Blood-brain barrier breakdown after embolic stroke in rats occurs without ultrastructural evidence for disrupting tight junctions. PLoS One 8:e56419. https://doi.org/10.1371/journal.pone. 0056419

51. Michalski D, Härtig W, Krueger M, Hobohm C, Käs JA, Fuhs T (2015) A novel approach for mechanical tissue characterization indicates decreased elastic strength in brain areas affected by experimental thromboembolic stroke. Neuroreport 26:583-587. https:// doi.org/10.1097/WNR.0000000000000395

52. Michalski D, Grosche J, Pelz J, Schneider D, Weise C, Bauer U, Kacza J, Gärtner U et al (2010) A novel quantification of bloodbrain barrier damage and histochemical typing after embolic stroke in rats. Brain Res 1359:186-200. https://doi.org/10.1016/j.brainres. 2010.08.045

53. Krueger M, Bechmann I, Immig K, Reichenbach A, Härtig W, Michalski D (2015) Blood-brain barrier breakdown involves four distinct stages of vascular damage in various models of experimental focal cerebral ischemia. J Cereb Blood Flow Metab 35:292-303. https://doi.org/10.1038/jcbfm.2014.199

54. Krueger M, Mages B, Hobusch C, Michalski D (2019) Endothelial edema precedes blood-brain barrier breakdown in early time points after experimental focal cerebral ischemia. Acta Neuropathol Commun 7:17. https://doi.org/10.1186/s40478-019-0671-0

55. Sacco RL, Kasner SE, Broderick JP, Caplan LR, Connors JJ, Culebras A, Elkind MS, George MG et al (2013) An updated definition of stroke for the $21^{\text {st }}$ century: a statement for healthcare professionals from the American Heart Association/American
Stroke Association. Stroke 44:2064-2089. https://doi.org/10. 1161/STR.0b013e318296aeca

56. Posmantur R, Hayes RL, Dixon CE et al (1994) Neurofilament 68 and neurofilament 200 protein levels decrease after traumatic brain injury. J Neurotrauma 11:533-545. https://doi.org/10.1089/neu. 1994.11.533

57. O'Collins VE, Macleod MR, Donnan GA et al (2006) 1,026 experimental treatments in acute stroke. Ann Neurol 59:467-477. https:// doi.org/10.1002/ana.20741

58. Endres M, Engelhardt B, Koistinaho J, Lindvall O, Meairs S, Mohr JP, Planas A, Rothwell $\mathrm{N}$ et al (2008) Improving outcome after stroke: overcoming the translational roadblock. Cerebrovasc Dis 25:268-278. https://doi.org/10.1159/000118039

59. Fisher M, Feuerstein G, Howells DW, Hurn PD, Kent TA, Savitz SI, Lo EH, STAIR Group (2009) Update of the stroke therapy academic industry roundtable preclinical recommendations. Stroke 40:2244-2250. https://doi.org/10.1161/STROKEAHA. 108.541128

60. Hjalmarsson C, Bjerke M, Andersson B, Blennow K, Zetterberg H, Åberg ND, Olsson B, Eckerström C et al (2014) Neuronal and gliarelated biomarkers in cerebrospinal fluid of patients with acute ischemic stroke. J Cent Nerv Syst Dis 6:51-58. https://doi.org/10. 4137/JCNSD.S13821

61. Mondello S, Gabrielli A, Catani S, D'Ippolito M, Jeromin A, Ciaramella A, Bossù $P$, Schmid $K$ et al (2012) Increased levels of serum MAP-2 at 6-months correlate with improved outcome in survivors of severe traumatic brain injury. Brain Inj 26:16291635. https://doi.org/10.3109/02699052.2012.700083

62. Gaiottino J, Norgren N, Dobson R, Topping J, Nissim A, Malaspina A, Bestwick JP, Monsch AU et al (2013) Increased neurofilament light chain blood levels in neurodegenerative neurological diseases. PLoS One 8:e75091. https://doi.org/10.1371/journal.pone.0075091

63. Lambertsen KL, Soares CB, Gaist D, Nielsen HH (2020) Neurofilaments: the C-reactive protein of neurology. Brain Sci 10. https://doi.org/10.3390/brainsci10010056

64. Kühn J, Meissner C, Oehmichen M (2005) Microtubule-associated protein 2 (MAP2)-a promising approach to diagnosis of forensic types of hypoxia-ischemia. Acta Neuropathol 110:579-586. https:// doi.org/10.1007/s00401-005-1090-9

65. Huh JW, Raghupathi R, Laurer HL, Helfaer MA, Saatman KE (2003) Transient loss of microtubule-associated protein 2 immunoreactivity after moderate brain injury in mice. J Neurotrauma 20: 975-984. https://doi.org/10.1089/089771503770195821

66. Fluri F, Schuhmann MK, Kleinschnitz C (2015) Animal models of ischemic stroke and their application in clinical research. Drug Des Devel Ther 9:3445-3454. https://doi.org/10.2147/DDDT.S56071

67. Schlaepfer WW, Lee C, Trojanowski JQ, Lee VMY (1984) Persistence of immunoreactive neurofilament protein breakdown products in transected rat sciatic nerve. J Neurochem 43:857-864

68. Banik NL, Hogan EL, Powers JM, Whetstine LJ (1982) Degradation of cytoskeletal proteins in experimental spinal cord injury. Neurochem Res 7:1465-1475. https://doi.org/10.1007/ BF00965089

69. Lian T, Qu D, Zhao X, Yu L, Gao B (2015) Identification of sitespecific stroke biomarker candidates by laser capture microdissection and labeled reference peptide. Int J Mol Sci 16:13427-13441. https://doi.org/10.3390/ijms160613427

70. Sharp FR, Lu A, Tang Y, Millhorn DE (2000) Multiple molecular penumbras after focal cerebral ischemia. J Cereb Blood Flow Metab 20:1011-1032. https://doi.org/10.1097/00004647200007000-00001

71. del Zoppo GJ, Sharp FR, Heiss W-D, Albers GW (2011) Heterogeneity in the penumbra. J Cereb Blood Flow Metab 31: 1836-1851. https://doi.org/10.1038/jcbfm.2011.93

72. Bråtane BT, Bastan B, Fisher M et al (2009) Ischemic lesion volume determination on diffusion weighted images vs. apparent 
diffusion coefficient maps. Brain Res 1279:182-188. https://oi. org/10.1016/j.brainres.2009.05.002

73. Gerriets T, Stolz E, Walberer M, Müller C, Kluge A, Bachmann A, Fisher M, Kaps M et al (2004) Noninvasive quantification of brain edema and the space-occupying effect in rat stroke models using magnetic resonance imaging. Stroke 35:566-571. https://doi.org/ 10.1161/01.STR.0000113692.38574.57

74. Kim C-B, Park S-J, Jeong J-C, Choi SM, Krause HJ, Song DY, Hong H (2019) Construction of 3D-rendering imaging of an ischemic rat brain model using the planar FMMD technique. Sci Rep 9: 19050. https://doi.org/10.1038/s41598-019-55585-x

75. Nabavi DG, Cenic A, Henderson S, Gelb AW, Lee TY (2001) Perfusion mapping using computed tomography allows accurate prediction of cerebral infarction in experimental brain ischemia. Stroke 32:175-183. https://doi.org/10.1161/01.str.32.1.175

76. Aronowski J, Strong R, Grotta JC (1997) Reperfusion injury: demonstration of brain damage produced by reperfusion after transient focal ischemia in rats. J Cereb Blood Flow Metab 17:1048-1056. https://doi.org/10.1097/00004647-199710000-00006

77. Memezawa H, Minamisawa H, Smith ML, Siesjö BK (1992) Ischemic penumbra in a model of reversible middle cerebral artery occlusion in the rat. Exp Brain Res 89:67-78. https://doi.org/10. 1007/BF00229002

78. Kuhle J, Gaiottino J, Leppert D, Petzold A, Bestwick JP, Malaspina A, Lu CH, Dobson R et al (2015) Serum neurofilament light chain is a biomarker of human spinal cord injury severity and outcome. $\mathrm{J}$ Neurol Neurosurg Psychiatry 86:273-279. https://doi.org/10.1136/ jnnp-2013-307454

79. Kuhle J, Barro C, Andreasson U, Derfuss T, Lindberg R, Sandelius $\AA$, Liman V, Norgren $\mathrm{N}$ et al (2016) Comparison of three analytical platforms for quantification of the neurofilament light chain in blood samples: ELISA, electrochemiluminescence immunoassay and Simoa. Clin Chem Lab Med 54:1655-1661. https://doi.org/ 10.1515/cclm-2015-1195

80. Johnson GV, Jope RS (1992) The role of microtubule-associated protein 2 (MAP-2) in neuronal growth, plasticity, and degeneration. J Neurosci Res 33:505-512. https://doi.org/10.1002/jnr.490330402

81. Murphy TH, Corbett D (2009) Plasticity during stroke recovery: from synapse to behaviour. Nat Rev Neurosci 10:861-872. https://doi.org/10.1038/nrn2735

82. Liang D, Bhatta S, Gerzanich V, Simard JM (2007) Cytotoxic edema: mechanisms of pathological cell swelling. Neurosurg Focus 22: E2:1-9. https://doi.org/10.3171/foc.2007.22.5.3
83. Stokum JA, Gerzanich V, Simard JM (2016) Molecular pathophysiology of cerebral edema. J Cereb Blood Flow Metab 36:513-538. https://doi.org/10.1177/0271678X15617172

84. Astrup J, Siesjo BK, Symon L (1981) Thresholds in cerebral ischemia - the ischemic penumbra. Stroke 12:723-725. https://doi.org/ 10.1161/01.STR.12.6.723

85. Sánchez C (2000) Phosphorylation of microtubule-associated protein 2 (MAP2) and its relevance for the regulation of the neuronal cytoskeleton function. Prog Neurobiol 61:133-168. https://doi.org/ 10.1016/S0301-0082(99)00046-5

86. Cabrales Fontela Y, Kadavath H, Biernat J et al (2017) Multivalent cross-linking of actin filaments and microtubules through the microtubule-associated protein Tau. ncomms 8:1981. https://doi. org/10.1038/s41467-017-02230-8

87. Wagner OI, Rammensee S, Korde N, Wen Q, Leterrier JF, Janmey PA (2007) Softness, strength and self-repair in intermediate filament networks. Exp Cell Res 313:2228-2235. https://doi.org/10. 1016/j.yexcr.2007.04.025

88. Shi Y, Zhang L, Pu H et al. (2016) Rapid endothelial cytoskeletal reorganization enables early blood-brain barrier disruption and long-term ischaemic reperfusion brain injury. ncomms 7:10523. https://doi.org/10.1038/ncomms10523

89. Guo C-Y, Xiong T-Q, Tan B-H, Gui Y, Ye N, Li SL, Li YC (2019) The temporal and spatial changes of actin cytoskeleton in the hippocampal CA1 neurons following transient global ischemia. Brain Res 1720:146297. https://doi.org/10.1016/j.brainres.2019.06.016

90. Holtzmann K, Gautier HOB, Christ AF, Guck J, Káradóttir RT, Franze K (2016) Brain tissue stiffness is a sensitive marker for acidosis. J Neurosci Methods 271:50-54. https://doi.org/10.1016/ j.jneumeth.2016.07.002

91. Spedden E, White JD, Naumova EN, Kaplan DL, Staii C (2012) Elasticity maps of living neurons measured by combined fluorescence and atomic force microscopy. Biophys J 103:868-877. https://doi.org/10.1016/j.bpj.2012.08.005

92. Kilkenny C, Browne WJ, Cuthill IC, Emerson M, Altman DG (2010) Improving bioscience research reporting: the ARRIVE guidelines for reporting animal research. PLoS Biol 8:e1000412. https://doi.org/10.1371/journal.pbio.1000412

Publisher's Note Springer Nature remains neutral with regard to jurisdictional claims in published maps and institutional affiliations. 